\title{
MATURATIONAL CONSTRAINTS ON LANGUAGE DEVELOPMENT
}

\author{
Michael H. Long \\ University of Hawaï, Manoa
}

\begin{abstract}
This article reviews the second language research on age-related differences, as well as first language work needed to disambiguate some of the findings. Five conclusions are drawn. (a) Both the initial rate of acquisition and the ultimate level of attainment depend in part on the age at which learning begins. (b) There are sensitive periods governing language development, first or second, during which the acquisition of different linguistic abilities is successful and after which it is irregular and incomplete. (c) The age-related loss in ability is cumulative (not a catastrophic one-time event), affecting first one linguistic domain and then another, and is not limited to phonology. (d) The deterioration in some individuals begins as early as age 6-not at puberty as is often claimed. (e) Affective, input, and current cognitive explanations for the reduced ability are inadequate. The capacity for language development is maturationally constrained, and its decline probably reflects a progressive loss of neural plasticity, itself possibly associated with increasing myelination.
\end{abstract}

\section{THE IMPORTANCE OF MATURATIONAL CONSTRAINTS}

The existence, scope, and source of maturational constraints on language development are important issues for both second language acquisition (SLA) theory and language teaching practice. As just one of many potential manifestations of biological scheduling, if there is a "sensitive period" for SLA, theorists may need to posit alternate learning mechanisms or processes for older learners, such as the use of

I thank Charles Pooser, assistant to the editor of SSLA, for his detailed work on the preparation of the manuscript. For their helpful discussion of the issues and/or for their comments on an earlier version of this article, I am very grateful to Robert Bley-Vroman, Craig Chaudron, Graham Crookes, Lars Ekstrand, Fred Genesee, Kevin Gregg, Barbara Horvarth, Bob Jacobs, Patsy Lightbown, Jurgen Meisel, Ernst Reese, Charlie Sato, Jackie Schachter, Dick Schmidt, Catherine Snow, and two anonymous SSLA reviewers. Very much reflecting the current state of the art in this area, none agrees wholly with the conclusions reached here, and some disagree strongly with one or more of them, although often for different reasons. It is more than usually important, therefore, for me to stress my own responsibility for any errors of fact or interpretation that remain. 
general inductive problem-solving instead of or in addition to universal grammar in some theories (Clahsen \& Muysken, 1986). Alternatively, if no sensitive periods exist, theories that claim that first language acquisition (FLA) and SLA are essentially similar processes, e.g., because universal grammar is available in some form to learners of any age (Cook, 1988; White, 1985), have at least prima facie validity. It is difficult to evaluate theories that say nothing about the issue.

Similarly, just about any position taken on age-related differences has potential implications for practice. For instance, a belief that postpubertal language learning will inevitably be incomplete where phonology is concerned (e.g., Scovel, 1988) might lead to recommendations for an early start for foreign language and second language (SL) programs, and/or the replacement of a native-like accent as a goal for adult classroom learners, with something more realistic. Rejection of the sensitive period idea, on the other hand, might influence the choice of methodology in first language (FL) intervention programs for mentally retarded adult populations or for normal adult SL learners and lead to greater flexibility in the timing of FL/SL programs.

Despite the apparent need to resolve these issues, few ideas in FL or SL learning have engendered more controversy. Differences in interpretation are nothing new in any research area, of course. Here, however, disagreements as to both the facts and their explanation are very pronounced.

\section{AN INTERACTIONIST VIEW OF MATURATIONAL CONSTRAINTS}

In a seminal article, Oyama (1979) traced the history and status of the critical and sensitive period concepts in developmental studies. The critical period notion had its origins in embryological development (e.g., loss of plasticity in body tissues as they become functionally differentiated) and, in ethology, in the work of Lorenz, Tinbergen, and others on imprinting and other instinctive behaviors in birds and fish. The definition, Oyama showed (p. 87 et passim; see also Colombo, 1982; Immelmann \& Suomi, 1981), was initially strict and narrow: the behavior had to appear in infancy, to be short and abrupt, to have permanent consequences, and to show "developmental fixity," i.e., because genetically determined, to be impervious to environmental influences. For this reason, the critical period concept is often still associated exclusively with "innate," "unlearned," "instinctive," or otherwise "genetically determined" phenomena.

Saying something is "biological" or "maturational" does indeed often imply reliably scheduled sequences, changes in anatomical structure and size, and apparent independence from specific environmental contingencies. The terms need not be so narrowly construed, however, Oyama noted, especially when applied to human behavior. Even where animal behavior is concerned, subsequent research in ethology has relaxed the definition. Imprinting is now recognized as often being quite gradual, variable, and open to environmental influences, and as not necessarily irreversible or instantaneous. Sensitive periods, according to Immelmann and Suomi (1981), do not generally have sharply defined upper and lower bounds and differ somewhat from one species, individual, and functional system to another. Variability, Oyama (1979, p. 
91) pointed out, is as much an inherent part of biological processes as regularity, and the need felt to recognize this is one reason for the growing preference for the term "sensitive" (over critical) period. Another reason, according to Patkowski (1990), is the fact that the age limitation posited by many on the capacity for SLA is not usually believed to be absolute in the same way as the age limitation on FLA. Thus, to be testable, a sensitive period must be claimed to be universal and regular within limits, but it need not be uniform to be interesting.

In sum, while maturational constraints are certainly compatible with nativist accounts of learning, they do not entail such views. Oyama suggested that a sensitive period is more usefully thought of as the product of a nature-nurture interaction, a time of heightened responsiveness to certain kinds of environmental stimuli, bounded on both sides by states of lesser responsiveness. Furthermore, she noted, where the identification of sensitive periods is concerned, no specific degree of abruptness is required in the changes in sensitivity-gradual increases or declines may be expected in some cases-provided the differences are marked enough to allow identification of the period from the periods preceding and following it.

Indeed, while the terms "sensitive period" and "critical period" are used interchangeably throughout most of the ethological and psychological literature, a growing preference for "sensitive period" even among ethologists (and by Lenneberg in his later writings) reflects the recognition that many of the changes will tend to be both less absolute and less than abrupt because they are often not genetically determined or developmentally fixed.

Age-related declines in language learning ability, therefore, may be expected to be correspondingly variable in onset and effect. One would no longer necessarily predict, for example, that all areas of language will be affected at the same time (say, puberty) in all individuals. Nor would one need to show a catastrophic one-time loss in ability in order to claim that a sensitive period exists for FL or SL learning. Thus, while somewhat weaker than the claim for a critical period for FL learning, the claim for a sensitive period for SLA is still a strong and interesting one. The maturational processes underlying it are held to be universal. Hence, learners who begin an SL after its supposed closure (which will here be claimed to be as early as age 6 for phonology in many individuals and around 15 for morphology and syntax), and who nevertheless attain native-like ability in those areas, will falsify the hypothesis.

\section{SOME STARTING HYPOTHESES FOR LANGUAGE LEARNING}

While some critics find the idea of maturational constraints counterintuitive, not to mention empirically unfounded, a case can be made for just the opposite view, i.e., that positing maturational constraints, including one or more sensitive periods for human language development, is the unmarked hypothesis. One would expect there to be such constraints, among other reasons, because they are so well attested in the development of other animal species, in other types of human learning, and in other human neurological abilities (see, e.g., Colombo, 1982; Gould \& Marler, 1987; Hinde, 1970; Mimura, 1986; Oyama, 1979). Writing of human development, specifically children's ability to recover from disease in the central nervous system, Lenneberg 
(1967) suggested that when studying human development, it is natural to expect maturation to play a role: "if we look at behavior from a biological point of view, we should be surprised if we did not find critical periods"; he further noted that development consists of "one long chain of phases in which one or another set of factors is of critical importance" (pp. 168-169).

Oyama (1979, p. 92), too, argued for the reasonableness of the expectation of maturational constraints on language learning. She observed that psychologists and educators generally accept that maturation constrains the onset of many other human developmental sequences. In medicine, similarly, it is common to speak of periods within which remedial treatment must be administered if satisfactory results are to be obtained and of age limitations to recovery from certain kinds of trauma (e.g., brain lesions). The same is true of resulting impediments, such as aphasias. The prognosis differs substantially, depending on the age at which the injury was suffered. What is not so popular, Oyama suggested, is the idea that such states of readiness may not last forever.

An obvious reason why skeptics might initially reject the idea of a sensitive period for SLA is that Lenneberg's original claim applied to FL development. Specifically, Lenneberg (1967) believed that the capacity for (first) language learning was lost if it was not activated, or exercised, during the critical period, which, he believed, ran from age 2 until 13. Lamendella (1977) wrote:

[S]ince no structural or functional atrophy of neural systems has taken place in the language systems of normal adults, and, since many adults clearly can reach high levels of second language competence, it is not legitimate to talk about a critical period in this context. A better approach is to ask whether there is a sensitive period for nonprimary language acquisition. (p. 216)

Critics of the claim for SLA might hold that, once activated, or exercised, the capacity could be expected to remain permanently available for subsequent learning of additional languages-a position Johnson and Newport (1989, p. 64) termed the "exercise hypothesis"-making the idea of sensitive periods for SLA moot. Another possibility, however, is that the capacity for language development, like many human abilities, is biologically scheduled for use during a certain period and, used or not, declines or disappears altogether at a certain age-a position referred to by Johnson and Newport $(1989$, p. 64$)$ as the "maturational state hypothesis."

Johnson and Newport have pointed out that Lenneberg himself was somewhat ambiguous on this issue. He wrote (Lenneberg, 1967) that "automatic acquisition from mere exposure to a given language seems to disappear after [puberty]" (p. 176), but also that the obvious ability of many to learn foreign languages in adulthood "does not trouble our basic hypothesis on age limitation because we may assume that the cerebral organization for language learning as such has taken place during childhood, and since natural languages tend to resemble one another in many fundamental aspects the matrix for language skills is present" (p. 176).

The exercise hypothesis-which asserts that once activated, the capacity for language learning remains permanently available-predicts differential success for child and adult FL learners, but equal success for child and adult SL learners. FLA by adult 
starters, e.g., the learning of American Sign Language (ASL) by congenitally deaf adults, will either be impossible (strong version) or less successful than child FLA (weak version), because it will be irregular and/or incomplete. SLA, on the other hand, will be unaffected by the age of the learner, according to this view, since the language learning capacity remains intact once activated.

The maturational state hypothesis-that whether exercised for FLA or not, the human language learning capacity declines with age-makes the same differential predictions for child and adult FL learning as the exercise hypothesis. Results for late FLA, therefore, could not choose between them. Unlike the exercise hypothesis, however, the maturational state hypothesis predicts that for SLA, younger learners, i.e., those learning (or at least beginning to learn) an SL during the sensitive period, will do better than older learners, i.e., those learning an SL after the capacity has deteriorated. Here is a case, then, where SLA research is crucial for solving a puzzle in FL development, although, as will become clear, FL findings will also help disambiguate some SL findings.

Several requirements must be fulfilled by those wishing to demonstrate maturational constraints on FL or SL development. To begin with, which of these two versions of the claim is being argued for and what exactly is meant by "incomplete" or "inferior" achievement must be specified. The position that will be argued here is that the literature supports the following quite radical version of the maturational state hypothesis, specifically:

There are sensitive periods governing the ultimate level of first or second language attainment possible in different linguistic domains, not just phonology, with cumulative declines in learning capacity, not a catastrophic one-time loss, and beginning as early as age 6 in many individuals, not at puberty, as is often claimed.

"Incompleteness" will refer to objectively identifiable differences between the underlying linguistic knowledge systems of SL speakers and monolingual native speakers of a language-the measurement of which raises crucial instrumentation issues, to which we will return. Differences might also be discernible in such areas as acquisition processes or learning mechanisms. Once the linguistic domain(s) and approximate age(s) involved in the claimed sensitive period(s) for SL development are specified, a single learner who began learning after the period(s) closed and yet whose underlying linguistic knowledge (not just performance on a limited production task) was shown to be indistinguishable from that of a monolingual native speaker would serve to refute the claim.

In addition, as Studdert-Kennedy $(1985$, p. 549$)$ pointed out, in order to substantiate the claim that there are sensitive periods for language learning, two other requirements must be met. First, unique sensitive periods must be shown, distinct from any general age-related increase or decline in cognitive abilities. Second, the biologically regulated receptivity of the learner must be demonstrated to be specific to linguistic, and not just any, stimuli.

With these goals and requirements in mind, what, then, are the facts? Is there 
evidence of maturational constraints on language development? Is there anything to explain?

\section{FIRST LANGUAGE DEVELOPMENT}

\section{Evidence of a Language-Specific Maturational Schedule}

There is now a considerable amount and variety of evidence that FL development follows a maturational schedule, and one, furthermore, that is specific to language, as opposed to general cognitive abilities. This is important for two reasons. First, showing that language learning in general follows a biological timetable makes the idea of biological constraints on language learning, as one aspect of the general schedule, prima facie more reasonable. Conversely, it would be illogical to expect to find maturational constraints in the absence of any other evidence of biological scheduling. Second, demonstrating the language-specificity of the schedule, its relative independence of general cognitive development, begins to meet the criteria proposed by Studdert-Kennedy (1985) for sensitive periods for language.

Findings on FL development in normal and abnormal populations support the following three generalizations, each in turn suggesting the existence of a maturational schedule for FL development. First, the age of onset of production, rate of acquisition, and age of completion of language learning are all fairly common across languages, cultures, and linguistic environments (Slobin, 1982). The emergence and initial course of development follow the same basic chronology even in situations where linguistic stimuli are largely lacking, as in the case of deaf children who receive no sign language input from their parents (Feldman, Goldin-Meadow, \& Gleitman, 1978). Second, errors, sequences, and levels of attainment are all fairly common in FLA, regardless of a child's cognitive abilities (Bellugi, 1967; James \& Kahn, 1982). Thus, while clearly not uniform (Fillmore, Kempler, \& Wang, 1979), FL development, unlike SLA, is remarkably homogeneous, even among learners with IQs ranging from 70-140-a variation that would affect other kinds of learning tasks. Even more impressive, a growing number of cases have been reported of children suffering from severe mental retardation whose language learning remains on schedule and unimpaired-so-called developmental dissociation of language and cognition (for a review, see Curtiss, 1988). Third, relatively little effect on development is observed for quite major environmental variation due to cultural or social class differences in childrearing patterns or in caretaker speech in normal FL settings (Gleitman, 1986), and, as noted earlier, the same is true in abnormal settings (Feldman et al., 1978).

\section{A Sensitive Period for FL-Test Cases}

The "strong" version of the critical period hypothesis (Lenneberg, 1967; Penfield \& Roberts, 1959) predicted that no FL learning would be possible if a child was not exposed to language before a certain age, usually given as puberty (i.e., around 13). The "weak" version held that some learning would be possible beginning after that age, but that native-like abilities would be unattainable, and that the course of development would become more irregular and would fall further short of native 
levels the later the age of onset. Given that exposure begins at birth in normal children, relevant test cases will by definition be from the literature on abnormal FL populations.

Feral children and child abuse cases. The data on children kept linguistically isolated from birth for varying periods of time are generally consistent with the "weak" version of Lenneberg's hypothesis. Learning is possible, but it becomes more irregular and falls further short of native levels of achievement the later it begins.

The case of "Isabelle" (Mason, 1942), showed that the offset time, for most language abilities, at least, is later than 6 . Imprisoned with her mute, uneducated mother, and the possessor of only a few primitive gestures until she was $61 / 2$, Isabelle showed accelerated development to normal levels of language and intelligence within 18 months following her release. Other cases of feral children (unfortunately, often poorly documented by the original chroniclers) are reviewed by Curtiss (1980), who found them to show that those children only achieved native-like abilities if they were recovered before age 10 .

The tragic case of "Genie" (Curtiss, 1977) is by far the best documented test of Lenneberg's original claim. After severe abuse and almost total isolation from the age of about 20 months, Genie was aged 13;7 on discovery and had no language. She subsequently succeeded in accelerated, somewhat irregular passage through normal language learning sequences, but stopped well short of native-like attainment, especially in morphology and syntax, only understanding plural morphology after training, for example, and almost never producing it. She was always better at vocabulary and semantics than syntax, and at comprehension than production. As Curtiss claimed, with the caveat that we are generalizing from a single, highly abnormal case, Genie showed that FLA is possible starting after puberty, but that learning will be irregular and incomplete. The data are consistent, i.e., with the weak version of Lenneberg's critical period hypothesis.

From a study of the kinds of linguistic features acquired and not acquired by Genie and other learners with impoverished input, Goldin-Meadow (1982) suggested that there are "resilient" features of language (e.g., word order production rules, constituent structure, and recursion) that seem to be resistent to learner or environmental variation that humans may therefore be "prepared" to learn, and "fragile" features (e.g., pro-forms, movement rules, auxiliaries, and other "closed class" items) that they may be less "prepared." Fragile features, Goldin-Meadow suggested, will not develop "without a linguistic model or beyond the critical period" (p. 74).

Hearing children of deaf adults. "Jim," aged $3 \frac{1 / 2}{2}$ when first studied by Sachs, Bard, and Johnson (1981), had been brought up in a fairly isolated rural area, the son of non-signing deaf parents. Otherwise denied normal input, Jim had succeeded in learning some 50 words and routines (allowing him to express simple semantic notions) but only minimal syntax from watching television. The provision of normal conversational experience thereafter was followed by rapid catch-up (attainment of age norms or better by age 6). Similar findings for a total of some 20 other children were reported by Goldin-Meadow (1982), Jones and Quigley (1979), and Schiff (1979). 
Deaf children of hearing adults with no ASL. Feldman, Goldin-Meadow, and Gleitman (1978) observed the emergence of "home sign" in six deaf children whose hearing parents did not know or use ASL. The youngsters were found to begin creating single gestures and two- and three-sign sequences at the same time and encoding the same meanings as hearing children start producing one-, two-, and three-word utterances. Importantly, however, the deaf children failed to develop "closed class" items by around age $4 / 5$, as hearing children would have done. The study suggests, in other words, that the basics of human language survive the absence of a language model, but that the environment is crucial for the elaboration of closed class items and complex syntax.

Deaf children's and adults' acquisition of ASL. Some of the clearest evidence for a sensitive period for FL development comes from work on the acquisition of ASL as a FL, the population concerned this time being free of the traumas and mistreatments suffered by children like Genie.

In an early study, Woodward (1973) reported that some ASL rules (agent-beneficiary directionality, negative incorporation, verb reduplication) were learned more often by individuals who started ASL before age 6 . Similar long-term advantages for young children over adult starters have been reported for the processing of ASL (e.g., Mayberry, Fischer, \& Hatfield, 1983). An ongoing study of "Chelsea," a hearingimpaired adult who began ASL as a FL in her early 30 s, revealed good lexical and semantic abilities after 6 years of exposure, but highly impaired morphology and syntax (Curtiss, 1988).

In an important large-scale project, Newport (1984) and Newport and Supalla (forthcoming) found clear evidence of sensitive periods for FL development. They studied congenitally deaf individuals exposed to ASL as a FL for equivalent periods of time (10 years), starting at different ages, all of whom were fluent in the language when tested. The results were striking. Group 1 (native/early learners first exposed to ASL between birth and 6) reached native standards and showed very uniform error types along the way, although learners whose first exposure was between 4 and 6 years of age already did slightly less well than those exposed at birth. The native/early group's errors of omission and sequentialization (producing the component morphemes sequentially rather than simultaneously) were important, since they suggested that this group was learning ASL via morphological analysis, in some cases even when most of the children's exposure was to older non-native or late acquirers who gave them somewhat deviant (morphologically unanalyzed) input. Group 2 (learners first exposed after 7) made some errors in closed class items (grammatical morphology) after 10 years of use and showed progressively more evidence of holistic (unanalyzed) learning the later they started. Group 3 (late/adult learners first exposed after age 12) stopped far short of native standards and showed much greater individual variation in error types, generally making few omission or sequentialization errors, but many errors arising from their use of frozen forms (signs holistically related to their meanings and not constructed from their component morphemes), with much of their production monomorphemic or of unanalyzed chunks containing $2+$ morphemes, which suggested holistic rote learning. Newport and Supalla (forth- 
coming) described this group's use of closed class items as sporadic, irregular, and often incorrect. Similar findings were reported by McKinney (1983) and Young (1981).

\section{Summary}

FL development is maturationally scheduled, and like most scheduled services, this one is not available at all times. The cases of Genie, feral children, deaf children of hearing adults with no ASL, and children and adults starting to acquire ASL at different ages combine to provide compelling evidence of maturational constraints on FL learning. They suggest a sensitive period or periods of wide scope, affecting morphology and syntax, and not just phonology. Further, they show that when first exposure is late, ultimate attainment will be incomplete, and that not even lengthy exposure and use can compensate for this.

Satisfying the requirements proposed by Studdert-Kennedy (1985), furthermore, these data strongly suggest the existence of maturationally scheduled languagespecific learning abilities. Various cases reviewed by Curtiss (1982, 1988) support the notion of the developmental dissociation of language and cognition. The data on Genie additionally indicate that the capacity for language learning atrophies (is subject to an offset time) independently of any decline in general cognitive abilities; i.e., it is only fully usable during one or more biologically timed sensitive periods for FL development.

Finally, it is important to note that the rate of development of what was learned was faster in Isabelle, Genie, Jim, and other late starters than in normal children, presumably because of the relatively advanced cognitive development associated with their older starting age. The rate advantage clearly does not falsify the sensitive period hypothesis, however. The crucial data for showing maturational constraints on FL development are the findings with regard to course of development and, especially, non-native-like ultimate attainment in Genie's case and those of other late starters, such as the adult ASL learners. In just the same way, the well-attested short-term advantage for adults over children in early SL morphology and syntax clearly does not nullify the idea of sensitive periods for SLA. The crucial data will again be those on ultimate attainment. Can learners who start a second or third language or dialect as older children or adults master that language or dialect to a level indistinguishable from that of a native speaker?

\section{SECOND LANGUAGE DEVELOPMENT}

As indicated earlier, opinion among SLA researchers as to the existence of maturational constraints in non-primary language learning is sharply divided. Some researchers (e.g., Johnson \& Newport, 1989; Patkowski, 1990; Scovel, 1988; Seliger, 1978) showed, what seemed clear to them, evidence of maturational constraintsmost obviously, but not only, data appearing to show that children but not adult starters can attain a native-like accent in the SL. Others (e.g., Hatch, 1983; McLaughlin, 1984; Singleton, 1989) thought the data mixed and ambiguous. A third 
group (e.g., Ellis, 1985; Flege, 1987; Genesee, 1988; Major, 1987; Neufeld, 1979; Snow, 1983,1987 ) claimed that the findings suggested an advantage for older learners and rejected the "younger is better" notion altogether, even for SL pronunciation ability. Genesee (1988), for example, concluded that:

[T]he existing evidence indicates that (1) all aspects of second language learning appear to be learned more efficiently and, therefore, possibly more easily, at least in the initial stages, the older the learner; and (2) native-like levels of proficiency in the phonological, syntactic and comprehension aspects of the second language can be attained in postpubertal learners. (p. 104)

Even among those who accept the existence of some kind of age effect, there is a considerable difference of opinion as to its scope and source. For scope, the issue is whether the decline in ability is limited to phonology. For source, affective, input, cognitive, and neurological explanations have each been proposed for age-related differences. The source question is, of course, of no concern to those who deny the existence of constraints altogether.

\section{Rate Differences}

After reviewing the literature then available on age differences, Krashen, Long, and Scarcella $(1979,1982)$ concluded that if short-term (rate) and long-term (ultimate attainment) studies were distinguished, the SLA literature supported three generalizations:

1. Adults proceed through early stages of morphological and syntactic development faster than children (where time and exposure are held constant).

2. Older children acquire faster than younger children (again in early stages of morphology and syntax, where time and exposure are held constant).

3. Child starters outperform adult starters in the long run.

Generalizations (1) and (2) refer to rate only, whereas generalization (3) refers to ultimate attainment, although it is neutral with regard to the absolute standards attainable by either group.

Quite a number of studies have appeared in the decade since the Krashen et al. (1979) review. The findings have almost all been consistent with the three generalizations, with the exception of some fuzziness in the area of phonology. While not directly relevant to the key issue of long-term attainment in the debate over maturational constraints, they provide valuable information about the possible upper and lower age bounds on the effects of constraints in different linguistic domains and so also need to be considered here.

As indicated, short-term studies, ranging in duration from a few minutes to a few months, speak only to differential rate of acquisition, and not to absolute abilities. They probably favor older learners because of their "teach and test" or laboratory interview formats and their occasional use of tasks where superior cognitive skills and/or test-wiseness can obviously play a role. In one such study comparing adults with children, Asher and Price (1967) taught Russian to a total of 134 8-, 10-, and 12year-olds and to (college age) adult students for 25 minutes, using Total Physical 
Response, and found that adults outperformed all the child groups. Snow and Hoefnagel-Hohle (1978) studied the naturalistic (untutored) acquisition of Dutch by 96 English-speaking children (8-10 years old), adolescents (12-15 years old), and adults, assessing each group's performance on pronunciation, morphology, imitation, and translation tasks after 3,6 , and $9 / 10$ months in Holland. In general, the adolescents and adults outperformed the children after 3,6 , and $9 / 10$ months in the country. Differences were decreasing at the second and third times of testing, however, and the children had already caught up with the adults on pronunciation by time 2 .

Similar short-term results favoring adults have also been found in studies of phonology involving either teaching and testing phonemic contrasts in a new language (Olson \& Samuels, 1973), assessing the acquisition of tone accents (Schmid, 1986), or simply testing subjects' ability to imitate target language sounds in nonsense words (Snow \& Hoefnagel-Hohle, 1977). The advantage is limited to older learners over children, however; younger adults go faster than older adults, as shown in a study of the English as a second language (ESL) listening comprehension skills attained by two groups of instructed French-speaking adult military personnel in Quebec (Seright, 1985; cf. Genesee, 1988, p. 104, conclusion 1).

Representative studies consistent with generalization (2), favoring older over younger children in rate of acquisition of morphology and syntax, are those of Ekstrand (1976), Fathman (1975), and Morris and Gerstman (1986). Ekstrand (1976) studied 2,189 8-17-year-olds learning Swedish as an SL over a 2-year period. He found a steady improvement with age and also found that older children performed better than younger children on measures of listening comprehension, reading, free writing, pronunciation, and speaking. In an analogous ESL study, Fathman (1975) looked at 200 children, ages 6-15 and resident in the United States from 1-3 years, assessing their English morphology, syntax, and pronunciation using the SLOPE (a picture-cued, sentence-completion test) and a picture description task. The 11-15year-olds outperformed 6-10-year-olds on morphology and syntax; the younger group did better at pronunciation.

In a more recent study, Morris and Gerstman (1986) compared the performance of 182 American public school children, ages $9(n=61), 12 / 13(n=73)$, and $16(n=$ 48), on a 20-minute lesson in Hawaiian, testing the children immediately after the lesson and a second time 1 week later. Instructional materials, which were presented auditorily, pictorially, and orthographically, consisted of a cartoon story (target language models), an English-Hawaiian vocabulary list (also available to students during testing to avoid a memory problem), and explicit rule statements (grammatical explanations) on the main foci of the lesson: the stative/transitive verb and locative $i$ versus $m a$ contrasts in Hawaiian. The test was written, and consisted of 14 multiplechoice items, 7 sentence-unscrambling (word order) items, and 7 error-detection (semantic acceptability judgment) items. Of the total of 28 items, half were syntactic and half semantic, half easy and half difficult, half linguistic and half metalinguistic, and half involved rule learning and half rote learning.

Using the first test scores as a covariate in the analysis of the delayed test scores to help eliminate the memory factor, Morris and Gerstman found that the two older groups did significantly better than the 9 -year-olds, and that the $12 / 13$-year-olds did 
best overall, but not significantly better than the 16-year-olds. Results for moderator variables (type of learning, task, and subtest) were inconsistent, but sentence-unscrambling was easier for all students, and semantic error detection was easier for the youngest group than for the two older groups. Motivation to learn Hawaiian was significantly negatively correlated with test scores, and attitudinal measures were uncorrelated. Multiple regression analyses revealed consistent predictive power across age levels for English reading ability, knowledge of an SL, and socioeconomic status (SES), among other factors, however, showing that, while powerful, age effects can sometimes be mitigated by a variety of cognitive, demographic, and task factors.

Similar or related findings favoring older over younger children for rate of learning have been reported by Bland and Keislar (1966), Snow and Hoefnagel-Hohle (1978), Ervin-Tripp (1974), Adiv (1980), Harley (1982, 1986), Ramirez and Politzer (1978), Fathman and Precup (1983), Ekstrand (1976), Asher and Price (1967), Burstall, Jamieson, Cohen, and Hargreaves (1974), Olson and Samuels (1973), Florander and Jansen (1969), Grinder, Otomo, and Toyota (1962), Weber-Olsen and Ruder (1980), Thogmartin (1982), Lowenthal and Bull (1984), and Collier (1987).

A set of findings apparently conflicting with generalization (2) are those of Walberg, Hase, and Pinzur Rasher (1978), who found no effect for age of onset (AO) on the ESL of Japanese children in U.S. schools, but an effect for length of residence (LOR). As noted by Krashen et al. (1979, p. 581), however, at least two factors explain the contradiction. First, when tested, most of the children had been in the United States from 3 to 4 years, and some for as long as 12 years, sufficient for the younger children to have caught up with the older ones. Second, the teacher ratings used in the study assessed the children's progress in terms of age/grade norms for American children. Since norms for older children are higher, the fact that the Japanese children showed no effect for age really means that the older children had gone faster, consistent with generalization (2), having reached their (higher) standards in the same amount of time as the younger children had reached their lower ones.

Findings for pronunciation in these age groups are at first sight somewhat confusing. Most studies report a rate advantage for older over younger children in phonology like that in morphology and syntax, but some do not, and, as usual, the waters are further muddied by a third set of long-term findings showing an advantage for younger children. In order to explain the results for rate, it is necessary to invoke two moderating variables, amount of exposure and task.

Studies showing an initial rate advantage in phonology for older over younger children share two properties. First, they tested children who had either had (through classroom instruction or residence abroad) or been given (in the laboratory) sufficient exposure to the target sounds to let their superior cognitive and test-taking skills operate, but not so much time that they could be overtaken by the younger children, who eventually outperform them in phonology, as elsewhere. Studies showing a short-term rate advantage for older children for phonology in this way, with the approximate amount of exposure involved in each case, are Olson and Samuels (1973)-10 hours; Ervin-Tripp (1974)-maximum of 9 months; Ekstrand (1976, 1978)-less than 2 years; Grinder, Otomo, and Toyota (1962)-1 year; and Snow and Hoefnagel-Hohle (1978)-3-10 months. 
In a study that sampled children from a similar age range, but included subjects with longer periods of exposure (1-3 years), Fathman (1975) found that 6-10-year-old starters had overtaken 11-15-year olds. A period from 1-3 years had apparently been long enough for the younger immigrant children going to school in the United States to catch up with older children in phonology.

The exact amount of exposure needed for younger children to catch up is unclear at present, and catch-up time actually overlaps across studies somewhat; 2 years was not enough in the study by Ekstrand (1976), whereas from 1-3 years was sufficient in Fathman (1975). More precise estimations are impossible on the basis of the existing data, however. Future research on this issue will need to use more exact measures of exposure than LOR and should avoid pooling data on large groups of subjects with varying amounts of exposure. The literature suggests, nevertheless, that the rate advantage for phonology is especially short-lived. In their study of the naturalistic acquisition of Dutch by English speakers, Snow and Hoefnagel-Hohle (1977) reported that the initial age differences favoring adolescent and adult learners for phonology disappeared after 4-5 months, with the younger children overtaking the two older groups on some sounds by $10 / 11$ months. In a study of Japanese children $(n=54$, $\mathrm{AO}=1-12)$ and adults $(n=24, \mathrm{AO}=18-43)$ acquiring English $/ \mathrm{r} /$ and $/ 1 /$, Cochrane (1980) found the children outperformed the adult group, with an average of about 200 hours of exposure compared with the adults' average of about 250 hours.

In apparent conflict with the pattern outlined above, however, two short-term (laboratory) studies (Tahta, Wood, \& Lowenthal, 1981b; Yamada, Takatsuka, Kotabe, \& Kuruse, 1980) found immediate superiority for younger over older children in phonology. Thus, Tahta et al. (1981b) found that the ability of a group of 231 5-15year-old English school children to imitate French and Armenian pronunciation of isolated words and phrases after one model declined steadily with increasing age. The same children's ability to replicate intonation in longer phrases remained steady in the 5-8-year range and then dropped rapidly between 8 and 11, plateauing again in the 11-15-year range. The reverse pattern was observed in the number of models and trials the children required before they could produce the intonation patterns well, the most marked increase in the number of trials needed by older children coming from 8-11-year-olds (Tahta, Wood, \& Lowenthal, 1981a, 1981b). Tahta et al. (1981b) concluded that if acquisition begins by 6 , there is no transfer of accent; if after $12 / 13$, there is invariably accent transfer; and if between 7 and 11 , the accent is usually very slight. They wrote, "Our data then suggest a very heavy effect of biological maturation; up to age 7 and after 12 this effect seems to be overwhelmingly important" (p. 270).

These apparently conflicting findings were possibly due to the nature of the task both groups of researchers utilized. Yamada et al. and Tahta et al. (1981b) allowed subjects just four models and one model, respectively, of the words or phrases to be imitated. Hence, as suggested by Krashen et al. (1979), the data favoring younger over older children may simply have been demonstrating the younger children's superiority for mimicry. A third set of short-term laboratory results appears to threaten this explanation, however.

In a separate study of Dutch by English speakers, Snow and Hoefnagel-Hohle 
(1977) used 136 subjects, ages 5-31, with no knowledge of Dutch. Each subject listened to and repeated five different nonsense words using Dutch sounds on tape for a total of 20 times per word, with the subject's own imitations being recorded. These were later rated by one of three native speaker judges on a 5 -point scale, revealing a small linear improvement with age. The crucial difference between this study and those by Yamada et al. and Tahta et al. (1981b) probably lies in the 20 different exposures to the target sounds that the subjects received, which were apparently enough data for the older children and adults to begin to work on, whereas 1 or 4 models in the other studies were not. In fact, the findings of all three studies agreed in this respect, since Snow and Hoefnagel-Hohle reported that differences favoring the older subjects only began to emerge after the first 10 presentations.

The idea that the amount of exposure needs to be sufficient for older children's early rate advantage to manifest itself is further supported by a closer examination of the Snow and Hoefnagel-Hohle (1977) findings. The results showed that, while older subjects (in the 12-31 age range) did somewhat better than the youngest children (57-year-olds), there was actually very little difference between the latter group and 915-year-old children-the groups of interest for comparison with other older-younger children results. Snow and Hoefnagel-Hohle did not provide raw scores, but inspection of their graphed results (Snow \& Hoefnagel-Hohle, 1977, Figure 1), showed that scores for all subjects (ages 5-31) fall within a narrow range, between approximately 2.5 and 3.25 on a 5-point scale, and that 7-and 9-year-olds actually did better than 10 and 11-year-olds. Moreover, the statistical tests that were reported as demonstrating an improvement with age within the entire group of subjects in fact showed only that there was at least one significant difference between one younger and one older group (probably between 5-year-olds and adults), and not between each group and the next oldest. The statistical testing also showed that the overall increase in pronunciation ability with age was linear, not that older children did significantly better than younger children. In other words, 20 models were probably really only a sufficient basis for a small early rate advantage for older learners to offset the mimicry ability of the youngest children, not for the typically more noticeable rate advantage for older children.

In summary, most of the literature to date is still consistent with Krashen et al's (1979) generalizations (1) and (2), supporting the idea of a rate advantage for adults over children, and for older children over younger children, but with the advantage being temporary and applying primarily to developmentally early morphology and syntax. The advantage also operates in phonology, but seems to last for a shorter period and to require a certain minimum exposure to target language sounds before it is measurable.

Such findings have sometimes been claimed to pose a serious problem for the idea of maturational constraints on SLA (see, e.g., Flege, 1987; Genesee, 1988; McLaughlin, 1984; Snow, 1983, 1987). The argument has little merit, however. First, as some of the same writers have recognized, it ignores the greater importance (not to mention the findings) of the data on ultimate attainment for resolving that issue. Second, it involves an interpretation of an early rate advantage for SLA at odds with the interpretation widely accepted for the initial rate advantage for late starters noted 
earlier in cases of delayed FLA, including, crucially, cases where the less than nativelike ultimate attainment of some of the subjects concerned in fact provided clear evidence of one or more sensitive periods for primary language development.

While short-term learning efficiency data suggest bounds on age-related declines in learning ability and are important for many practical concerns, e.g., decisions about the timing of SL immersion programs (Genesee, 1983), the most important data for demonstrating maturational constraints on SLA are not those dealing with rate of development. Rather, they are of two kinds. Data concerning generalization (3), to the effect that children outperform adults in the long run, lend support to the claim that SLA, like FL development, is maturationally constrained. Data concerning absolute potential, i.e., whether adults (or child starters, for that matter) can reach native-like levels in an SL, provide the critical evidence for or against the existence of a sensitive period for SLA. It is to studies addressing these two issues that I now turn.

\section{Ultimate Attainment Differences}

Long-term studies (those comparing achievement after several years of foreign language study and/or residence in the SL environment) have found that younger starters consistently outperform older ones, and that only those who begin an SL as quite young children are ultimately capable of native-like attainment, even after many years of target language exposure. Learners starting later than age 6 often become communicatively fluent, but also often finish with measurable accents in phonology and, with progressively later starts (e.g., after age 15 for morphology and syntax), with "accents" in other linguistic domains, too.

Phonology. In one of the largest and most carefully conducted studies of this issue to date, Oyama (1976) looked at the pronunciation ability of 60 Italian immigrants with different age of arrival (AO) in the United States (range 6-20), and who had lived there for different periods (range 5-18 years). Oyama found a clear main effect for $\mathrm{AO}$ and no effect for LOR or motivation once the effect for $\mathrm{AO}$ had been partialled out. Child arrivals performed in the range of native speaker (NS) controls; those older than 12 on arrival did not, and accents were also evident in some who had arrived earlier than 12 .

Oyama's results are consistent with those of several other long-term SL and second dialect studies (e.g., Seliger, Krashen, \& Ladefoged, 1975). Of particular interest, the finding that some children starting considerably younger than puberty retained accents in the SL is by no means unique. First, Oyama's findings were replicated by Patkowski (1980a, in press), who also showed a clear discontinuity (not merely a gradual, age-related decline) in the accentedness ratings awarded to two groups of subjects, one with AO less than $15(n=33)$ and one with $\mathrm{AO}$ greater than $15(n=34)$. Earlier, Asher and Garcia (1969) found that 71 Cuban students with AO in the United States of 1-6 were judged closest to native-like on a sentence-repetition task, with stronger non-native accents being heard in progressively more subjects in groups with AOs of 7-12 and 13-19. In a Canadian study, Ramsey and Wright (1974) observed a sharp drop in the intonation perception abilities of immigrant children 
arriving in Toronto schools after age 7 (see Cummins, 1981, for a reanalysis of these data). Finally, in a study of the ability to acquire the phonology of a second dialect, Payne (1980) found that predictable, regularly conditioned vowel phonemes of the variety of English spoken in King of Prussia, Philadelphia, were learned by all children moving there from parts of the United States where other dialects are spoken. Unmotivated exceptions, however, were only mastered by children who arrived by age 6 and had locally born parents who spoke with the King of Prussia accent in the home.

The suggestion that age 6 is critical for phonology also receives support from several short-term studies. The sharp drop in imitation abilities observed by Tahta, Wood, and Lowenthal (1981a) can be accounted for by positing that maturational constraints begin to set in as early as 6 for suprasegmental phonology in some learners and soon after that for segmental phonology. Such a view would also account for the findings by Fathman (1975), for the impressionistic pronunciation assessments in Yamada et al. (1980), and for the findings of a short-term second dialect study by David (1985).

The beginning of a decline in phonological abilities by age 6 in some learners is considerably earlier than has traditionally been assumed by those believing in maturational constraints, but cannot be explained away as an artifact of insufficient SL or second dialect exposure. Some children in the 6-10 age group in Oyama's (1976) study, for example, were accented despite LOR of 12-18 years, and, as reported earlier, several of the long-term studies tested but found no effect for LOR. Note also that the results for late ASL morphology (Newport, 1984; Newport \& Supalla, forthcoming) show the onset of a decline for those first exposed after age 7.

In summary, the SL and second dialect results all suggest that SL phonological attainment is strongly conditioned by learner age. Specifically, a native-like accent is impossible unless first exposure is quite early, probably before 6 in many individuals and by about age 12 in the remainder. Very high standards can be attained starting later, of course, but not, it seems, native-like standards. Some ability appears to have been irreversibly lost.

Apparent counterevidence to the idea of a sensitive period for phonology is offered in a series of studies by Neufeld (1979). Neufeld's research requires close scrutiny since his findings, interesting in themselves, are also relied upon heavily by critics of the sensitive period notion for SLA (see, e.g., Ellis, 1985; Flege, 1987; Genesee, 1988; Snow, 1987).

Neufeld has demonstrated that high levels of pronunciation and intonation can be achieved by both foreign language and SL learners (a finding not inconsistent with the notion of a sensitive period for SLA, of course). In one study (Neufeld, 1977), after receiving 18 hours of intensive instruction in Japanese and Chinese phonology, 20 adult NSs of English practiced five times and then recorded ten phrases of four to eight syllables in length in each language, the tape later being played to three NSs of each language. Of the 20 subjects, 3 received an NS rating in one language, one of whom did so in both languages. In other studies (Neufeld, 1978, 1979), a small minority of tapes made by adult starters (the actual $\mathrm{AO}$ of subjects is not reported by Neufeld) with lengthy naturalistic French SL exposure and use were good enough to lead some 
individuals among groups of both linguistically sophisticated and linguistically naive judges to misclassify them as those of NSs when hearing a master tape of randomly ordered non-native speaker (NNS) and genuine NS "read aloud" speech samples. His findings have led Neufeld to claim that accent-free SL performance is possible, and that, therefore, there is no sensitive period for SLA.

This is arguably to overstate the case, however, since the studies suffer from some important limitations and possible methodological flaws. Most obvious among the former is the question of population validity, or the generalizability of Neufeld's findings. First, in the French studies (although not in the Chinese/Japanese study), the NNSs tested were an elite few, drawn from a true bilingual environment (the English/French-medium University of Ottawa), who, after responding to a public request for subjects who considered themselves highly proficient bilinguals, survived an initial screening interview for accentedness, and who were therefore by definition not representative even of the attenuated sample volunteering for the study, much less of the population at large. This in no way invalidates them as potential test cases for the sensitive period hypothesis, but severely limits any generalizations about typical adult SL pronunciation abilities.

Second, continuous immigration has resulted in heterogeneous English and French speech communities in cosmopolitan cities like Montreal, Toronto, and Ottawa, as well as tolerance for and expectation of within-language variation (a phenomenon by no means unique to Canada, of course). These factors may be expected to cause raters to think twice before rejecting accented English or French as definitely non-native.

Third, the speech samples in Neufeld's studies were extremely limited, consisting of tape recordings either of rehearsed imitations of short isolated phrases (in the Japanese/Chinese study) or of a 78-word rehearsed passage (in the French study), read aloud by the subjects, and in some cases rerecorded by them if it was not in their opinion as native-like as they felt capable of sounding. The judges had to identify these as NNSs, based on hearing the tiny, careful speech samples presented on tape and mixed in random order with renditions of the same passage read by NSs. How valid an indication even of those subjects' phonological competence is such a small sample of carefully rehearsed and monitored behavior? Is the test to be whether some subjects can fool some of the raters (actually, just $75 \%$ of the raters was the standard used in the French study) some of the time or, as would seem more reasonable, whether some subjects can fool all of the raters all of the time? "All of the time" obviously has to be circumscribed for the hypothesis to be testable at all, but not nearly as circumscribed, surely, as in Neufeld's research.

Finally, Neufeld's instructions to raters in both studies may have influenced the outcome. In the French study, judges were asked to rate the ten speech samples they would hear as those of "Canadian Francophones," "Francophones from another country," or "Non-Francophones." Inclusion of the second category may have reminded them of the wide variety of "accented" but still "native" French heard in Canada, again making them hesitant about classifying a sample as non-native. They were told there might be as many as 10 or as few as 0 NSs on the tape, possibly setting up an expectancy of a $50 / 50$ split, when there were in fact 7 non-native and $3 \mathrm{NSs}$, thereby 
increasing the likelihood of false identifications of non-natives as natives. Scovel $(1981$, p. 398) pointed out that in the teaching study the instructions were ambiguous and again potentially leading. Judges were told they were about to hear 20 speakers of Japanese/Chinese, "some of whom, as recent arrivals [to Canada] might not yet have learned English. Still others ... might be fluent speakers with detectable traces of interference" (Neufeld, 1977, p. 53). These instructions, Scovel noted, would presumably lead raters to suppose that they were hearing NSs of Japanese/Chinese (when all the speakers on the tape were in fact English speakers) and so set them up to classify NNSs as NSs. They might think, for example, that the voices were those of immigrants, NSs of Chinese or Japanese, now accented in their FL due to learning English. A preferred procedure, used by Scovel (1981) in his own research (see also Guiora \& Schonberger, 1989), is to use both NSs and NNSs, inform judges of this, and present them with the straightforward binary task of deciding which group each subject belongs to on the basis of his or her speech sample.

In summary, Neufeld's studies seem most valuable as demonstrations of the high standards both foreign language and SL learners sometimes achieve. Ironically, they may even underestimate adult abilities, for, as Flege (1987) noted, demonstration by Guiora, Beit-Hallahmi, Brannon, Dull, and Scovel (1972) of the SL pronunciationimproving effects for some subjects of limited amounts of alcohol suggests that adults' phonological competence in an SL exceeds their typical SL performance. Owing to the methodological problems indicated, Neufeld's findings do not, however, constitute counterevidence to the idea that there is a sensitive period for SL (and second dialect) acquisition.

The need not just for unambiguous instructions but also for an adequate speech sample in research of this kind was shown by a cleverly designed series of studies by Scovel (1981) of the ontogeny of the ability to recognize a spoken or written foreign accent. Scovel had four groups of judges (31 adult NSs, 146 child NSs of different ages, 92 adult NNSs and 23 adult aphasics) rate 20 8-second "read aloud" taped 31-word speech samples (recorded by the subjects after as many trials as they wished, as in Neufeld's research) as either those of NSs or NNSs of American English. The adult judges were also asked to try to distinguish the same 20 natives and non-natives on the basis of short written pieces, unspeeded free paragraphs on "the importance of sleep." There were 10 NSs and 10 NNSs of American English in the sample, and Scovel took several steps to make sure the NNSs were very good. First, he selected only extremely proficient speakers, all of whom used English professionally on a daily basis, had an LOR of at least 5 years, and had done graduate studies at U.S. universities. Second, two of the so-called NNSs (of American English) were actually NSs of Irish and South African English. Third, Scovel had three experienced ESL teachers screen the group to eliminate any subjects whose pronunciation was not excellent.

The child judges' ability to make correct identifications increased steadily from $73 \%$ accuracy at age 5 (the youngest children Scovel could get to understand the task) to near-perfect classification ( $97 \%$ accuracy) by age $9 / 10$. The adult NSs also had no problem with the oral samples ( $95 \%$ accuracy), but performed at chance level $(47 \%)$ on the written samples, presumably because, again, the writing represented the subjects' best, monitored production, and also allowed subjects to avoid problem 
areas that might have revealed them to be highly proficient but non-native. This interpretation is strengthened by Ioup's (1984) finding that linguistically sophisticated NSs could correctly classify interlanguage samples as belonging to one of two native language groups when phonological clues were available, but not when the only evidence was syntactic. Finally, Scovel found, adult NNSs improved in their detection ability with increasing ESL proficiency, but even the advanced group achieved an accuracy rate of only $77 \%$, similar to the 5 -year-old children's performance, and poorer than the $85 \%$ average of the group of aphasic patients. In addition to offering several methodological lessons for this type of research, Scovel's findings supplement those of a sensitive period for production of an SL or second dialect phonology by providing evidence of the age-related evolution of accent recognition in NSs and of a sensitive period for accent recognition in non-natives.

Morphology, syntax, and semantics. The cases of late FL development by Genie, Chelsea, and adult ASL acquirers reviewed by Curtiss (1988) all showed grammatical, and not just phonological, impairment. As might be predicted from this, the SL data provide increasing evidence that age-related barriers to SLA are not limited to phonology either, as some have claimed. Three studies, by Patkowski (1980a, 1980b, 1982), Coppieters (1987), and Johnson and Newport (1989), suggest strongly that a sensitive period affects SL morphology and syntax, too. This is not to say, of course, that syntactic development cannot continue late in life; it clearly can, as Wald (1986) demonstrated in his analysis of late emerging complex syntax in the speech of Spanish-English bilinguals in East Los Angeles. It appears, however, that native-like attainment of an entire second dialect or SL syntax is beyond the late starter.

In a large-scale study, Patkowski (1980a, 1980b, 1982) obtained global syntactic proficiency ratings of transcribed 5-minute excerpts from the spontaneous speech of 67 NNSs of English, immigrants to the United States, and 15 NS controls during interviews with NSs. Use of written transcripts removed any phonological clues as to the speakers' backgrounds or proficiency. Two trained raters employed something like the old U.S. Foreign Service Institute scale, from (0) no ability to (5) educated, native-like performance, to rate the ESL speakers. Unknown to them, the subjects had varying AO, LOR (minimum of 5 years), and amount of formal ESL instruction. Patkowski found a strong main effect for $\mathrm{AO}$ (negatively correlated with proficiency), no main effect for any other variables (LOR, informal exposure, or formal instruction), and no interaction effects. Most striking, as shown in the histogram (Figure 1), was the clear bimodal distribution among the NNS subjects, indicating that they represented two populations, identified by Patkowski as those who had arrived in the United States before age 15 and after. The younger group (average $\mathrm{AO}=8.6$ years) did statistically significantly better than those arriving after 15 (average $A O=27.1$ years) and were themselves outperformed by the NS controls, who received "perfect" (5) ratings (Patkowski, 1980a, p. 111).

Patkowski's results suggest that maturational constraints operate on SL morphology and syntax by showing higher long-term levels of proficiency for younger starters. The findings are also consistent with a hypothesized sensitive period for morphosyntax ending at around age 15 , but they do not by themselves rule out the possibility 

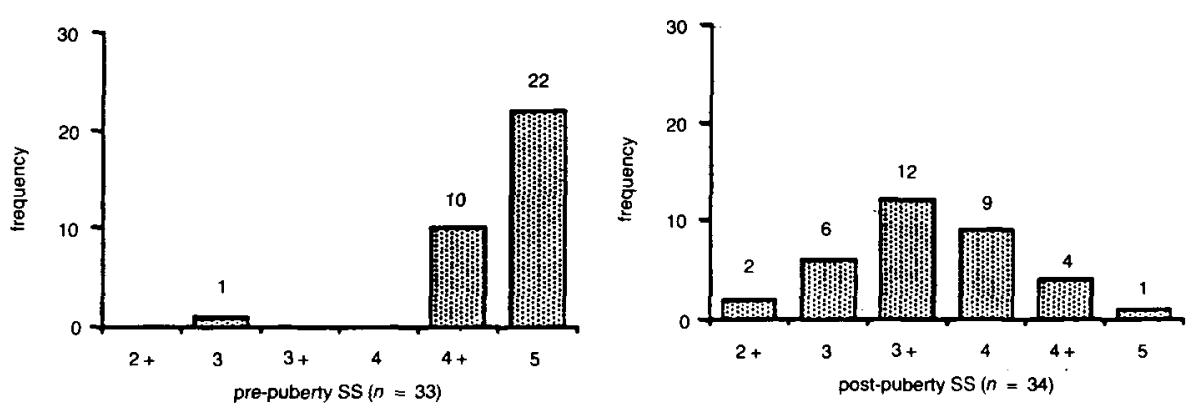

Figure 1. Syntax ratings for pre- and post-puberty learners (from Patkowski, 1980a, p. 111).

of ultimate native-like attainment for late starters, which would falsify the hypothesis. It is clear, after all, that more SL learners reach very high levels of proficiency in these domains than in phonology, as was seen in the results for written samples in the study by Scovel (1981) and the comparison of spoken and written samples by loup (1984).

Testing very advanced proficiency in morphology and syntax presents serious methodological problems, however. First, many of the morpho-syntactic constructions of potential interest are likely to be optional and so easily avoided in natural production data. They also tend to be low-frequency items. Hence, the use of competence measures, such as grammaticality judgment tasks, is indicated. Second, some constructions may be of the kind with which even some monolingual NSs occasionally have trouble, in turn raising the thorny issue of just how "native speaker" and "native-like" are to be defined in such research. In an effort to deal with this problem, it is necessary to ensure the comparability in a given study of NNSs and NSs from whom baseline data are obtained with respect to age at testing, general educational background, literacy, and so on, and to ascertain the grammatical status of target structures, using those baseline data, before including them in test items for the nonnative subjects. Third, test items must be objectively scorable as grammatical or ungrammatical, but researchers must not achieve this quality in their instruments merely by focusing on easily tested items, since such items may also simply be too easy for advanced speakers, who may therefore score very high or even perfectly on a test, yet still in fact be far from native-like. Finally, while NS language variation is omnipresent, such research needs to be conducted within as homogeneous a speech community as possible, and in one whose variety of the SL was the acquisition target for the NNSs being tested.

At least three pieces of research go some way towards addressing these concerns. First, Patkowski had his subjects complete a grammaticality judgment test and reported finding essentially the same pattern of results as for the syntactic ratings (Patkowski, 1980a, p. 91).

In another study probing advanced grammar, Coppieters (1987) began by using a written questionnaire to elicit grammaticality and semantic judgments from a group of 21 highly proficient, highly educated NNSs of French (mostly university faculty) from a variety of FL backgrounds, all of whom had learned French as adults. He then 
followed up with lengthy taped interviews (an average of 50 minutes) with each of his 21 NNS subjects and with 20 French NSs. In the interviews, Coppieters obtained detailed explanations and glosses on the judgments. Items covered included semantic distinctions between pairs of French sentences (contrasting il/elle with ce, preposed and postposed adjectives, imparfait and passé composé tense choices, and article use) and grammaticality judgments in such areas as causatives and clitic pronouns, object plus predicate constructions, and the A over A constraint.

Coppieters' subjects were all very advanced, 6 sufficiently so as to be reported by the researcher as having no "clearly detectable" accent in French after his conversation with them. Each, nonetheless, showed unmistakable evidence of being an NNS on the syntactic/semantic judgment tasks. While NS controls exhibited some variability on some items, the greatest NS variability on any item was easily exceeded by the least amount of variability shown by the NNSs on any item. The NNS closest to the prototypical NS norm on the quantifiable items (chiefly those concerning grammaticality judgments) was about three standard deviations away from the NS mean, showing, once again, that two distinct populations were being sampled. Because it lacked a prepuberty comparison group, the study might simply be viewed as having shown that NSs outperform NNSs on some kinds of tests. The findings are clearly consistent, however, as Coppieters says, with a hypothesized age-related decline in SLA syntactic abilities. Qualitative analysis of semantic judgments obtained in the interviews revealed even greater divergence from NS norms in the semantic domain, and Coppieters concluded: "[T]he extent of the gap between NSs and NNSs, particularly in the interpretation of basic grammatical contrasts, points to qualitative, not simply quantitative, differences between the two groups" (1987, p. 565).

The least ambiguous evidence to date of maturational constraints operating in the morpho-syntactic domain is that provided by Johnson and Newport (1989). Johnson and Newport obtained grammaticality judgments on a wide range of English morphology and syntax from 46 NSs of Korean or Chinese whose AO ranged from 3-39 and whose LOR in the United States ranged from 3-26 years at time of testing. Target structures included such items as articles, wh- questions, particle movement, and past tense, plural, and third person singular morphology. The 276 test items, which seem to have been rather easy in many cases, had subjects assess the grammaticality of such sentences as:

The woman paints

Paints the woman

Yesterday the hunter shot the deer

Yesterday the hunter shoots the deer

On all the structures tested, Johnson and Newport found a strong advantage for early over late arrivals. Most important, however, test scores were inversely linearly related to $\mathrm{AO}$ up to puberty, but after that, while low, they were very variable and unrelated to $\mathrm{AO}$, suggesting a sensitive period and not simply a general age effect (see Figure 2). There was no effect for LOR, motivation, self-consciousness, or American identification. 
a. Subjects Arriving Ages 3-15, $r=-.87$

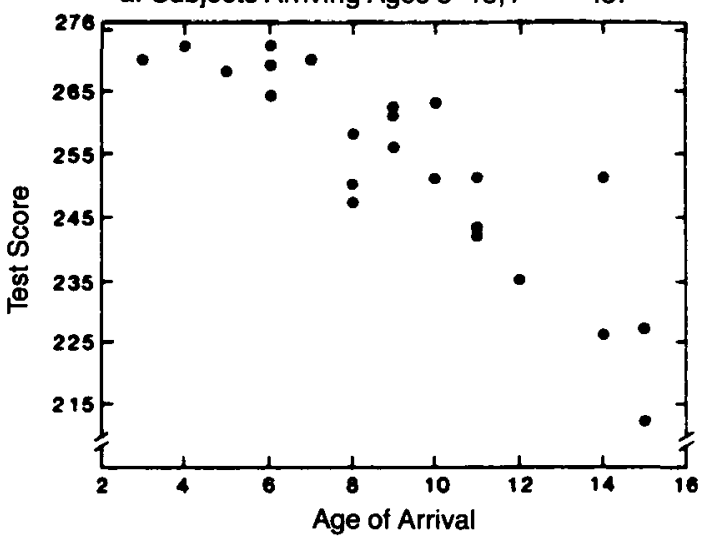

b. Subjects Arriving Ages 17-39, $r=-.16$

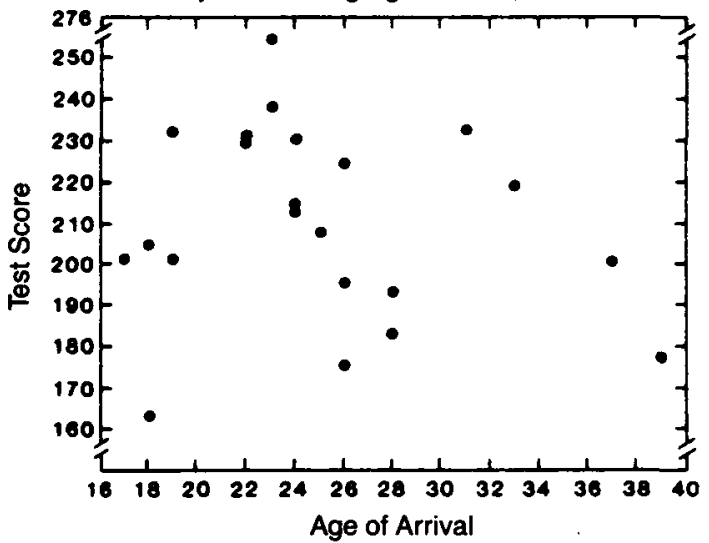

Figure 2. Grammaticality judgment scores and $\mathrm{AO}$ in two groups; note: the $\mathrm{Y}$ axes are on different scales (from Johnson and Newport, 1989, p. 80).

Aural abilities. In a second study with the same group of 60 Italian immigrants, Oyama (1978) found a strong negative effect for subjects' AO in the United States and their ability to comprehend masked speech. Children arriving before age 11 performed similarly to NS controls, with later arrivals showing a progressive (linear) decline with age. Once again, there was no LOR effect. In the only other relevant study, Scovel (1981) found that NS ability to recognize foreign accents reaches native levels at age 10, a criterion that was not achieved by his NNS subjects. A replication with more advanced learners would be useful, however.

Lexis and collocation. There appears to have been little or no published work on ultimate attainment in the area of lexis and collocation. Patkowski (1980a, pp. 
116-121) provided examples of lexical and collocation errors involving violations of selectional restrictions and taken from the transcripts of the 6 most proficient NNSs in his sample of 67 , as judged by their syntax ratings. Summarizing, Patkowski concluded that with NNSs of this ability level (very close to native norms), it is not so much qualitative differences in the errors that advanced NNSs and some NSs make, but rather the frequency of such errors in the interlanguage samples and the degree of deviance that distinguishes the NNSs (1980a, p. 121).

Two other unpublished studies are relevant, although, it should be noted, neither focused on age differences specifically nor compared groups with differing AO. Matsunobu (1981) found NS judges easily able to distinguish writing samples obtained under the same conditions from NS freshman composition students and NNSs who, after considerable LOR in the United States, had placed into the same remedial writing classes at a U.S. college. In solicited written comments and underlinings, judges further indicated that the basis of their classifications had been both the collocation errors in the NNSs' writing, which were absent in the NS samples, and, conversely, idiomatic phrasing in the NS samples that the NNS writing did not exhibit. (Matsunobu used three groups of raters, incidentally, finding ESL teachers best at classifying the samples as NS or NNS, followed by freshman composition teachers, with college-level content teachers bringing up the rear.) Matsunobu's findings were later confirmed in a small-scale replication using NNSs, "standard" English NSs, and NSs of Hawaii Creole English (Toutaiolepo, 1984).

More research in this area is clearly needed, but findings to date suggest that agerelated learning effects will be discernible here, as elsewhere, provided researchers collect adequate spoken or written samples. While NNS writing samples have passed as native in two studies (loup, 1984; Scovel, 1981), it seems that lexical voids and collocation errors will be less easy to conceal in longer, spontaneous speech samples, or even in writing samples, especially under speeded conditions, when the NNS is less adept at planned discourse and avoidance strategies.

Discourse and pragmatics. Very little empirical work has been done in the areas of discourse and pragmatics either, but the data so far again suggest the existence of maturational constraints. While again not primarily addressing the age factor, a study by Scarcella (1983) produced results consistent with the idea that late starters will not be able to achieve true native competence in such subtle (but as Scarcella shows, measurable) areas as culturally appropriate topic choice and sequencing, back-channel cues, and other conversational strategies. The 10 NNSs in her study had all arrived in the United States by age 7, in fact, and yet were still deficient in these areas after 12 to 17 years residence. They had what Scarcella describes as a "discourse accent."

\section{Summary}

Contrary to recent assertions in the literature, there is growing evidence that maturational constraints are at work in SL learning, and that they are not confined to phonology. Studies showing an initial rate advantage for adults over children and for 
older over younger children in early syntax and morphology should be interpreted as just that-a short-lived rate advantage. They do not show that older children or adults are better learners. On the contrary, starting after age 6 appears to make it impossible for many learners (and after age 12 for the remainder) to achieve native-like competence in phonology; starting later than the early teens, more precisely after age 15 , seems to create the same problems in morphology and syntax. Preliminary results suggest that similar generalizations will eventually be found to hold for lexis and collocation, and for certain discourse and pragmatic abilities.

While the superior long-term achievement of younger learners is consistent with the notion of maturational constraints on most dimensions of SLA, the apparent inability of older learners to attain native-like proficiency if they begin after a certain age further suggests that there is a sensitive period for learning. The precise limits of this period are still unclear. The available data suggest, however, that exposure needs to occur before age 6 to guarantee that an SL phonology can become native-like (given sufficient opportunity) before age 15 if the morphology and syntax are to be native-like, and somewhere between those ages for the remaining linguistic domains. That is to say, there is probably not just one sensitive period for SLA, but several: one for phonology, one for morpho-syntax, and so on. No doubt, as with sensitive periods in many aspects of human and other animal development, there is some overlap due to the relationships among sub-systems across linguistic domains, and some variation across individuals.

The easiest way to falsify such claims would be to produce learners who have demonstrably attained native-like proficiency despite having begun exposure well after the closure of the hypothesized sensitive periods. Given that some learners do reach very high levels in these domains, even starting in the early teenage years in some cases, and given that many problem areas (e.g., in syntax) occur infrequently and, unlike phonological difficulties, are often relatively easy to avoid, it is necessary to employ carefully designed elicitation tasks and comparable NS baseline data if any gaps in the competence of advanced NNSs are to be revealed. Anecdotal reports of individuals who have achieved native proficiency in morphology, syntax, etc., are typically based on impressionistic judgments of inadequate samples of inappropriate (production) data. Care also needs to be exercised to ensure that competence measures are not too easy, as appears to have been the case in the study by Johnson and Newport (1989), in which one subject with an AO of 23 made an almost perfect score on the test (see Figure 2). Judging from the grammatical areas listed and sample items given by Johnson and Newport, it is surprising that only one older starter did so well.

\section{EXPLANATIONS FOR AGE DIFFERENCES}

A sensitive period hypothesis does not explain the phenomena to which it is applied, but is itself to be explained (Bateson, 1973; Hinde, 1970, p. 564). Even among those scholars who agree that age-related differences in SLA do exist and/or subscribe to some version of a sensitive period hypothesis, there is serious disagreement as to the causes. At least four major clusters of variables have been implicated. 


\section{Social/Psychological/Affective Factors}

A number of writers (e.g., Brown, 1979; Schumann, 1975; Taylor, 1974) have claimed that success and failure in SLA is largely the result of social, psychological, or affective factors, with learner age being either irrelevant or only indirectly relevant, in that children and adults often differ in these areas. Variables such as attitude, motivation, empathy, self-esteem, ego-permeability, and perceived social distance enter into varied combinations to impede SLA in different ways in these writers' views, e.g., by acting as a "filter" that in some unspecified way stops input from reaching the brain areas responsible for language acquisition (Krashen, 1982, p. 31).

Problems with this explanation include the following reasons. (a) Children vary in these areas, but their language development does not (Gregg, 1984). (b) The claim offers no explanation as to why different linguistic domains are constrained at different ages, e.g., phonology before syntax, or why particular linguistic features are "filtered out" of the input while other features seem to be acquired by learners with, for example, very different attitudes towards speakers of the target language. (c) The precise claim is unclear. Just which of these variables, in what combinations, and to what degree, are supposed to affect learning, and why? For example, does it matter that a highly motivated learner with a positive attitude has just one supposedly "harmful" affective state for SLA (say, low self-esteem), or is the claim that an "average" value for the variables (however that might be calculated) needs only to be positive to ensure success? (See Schmidt, 1981, for a discussion of this problem.) The claims made for these variables will not be testable or falsifiable until these and other issues are clarified. (d) If both the lack of precision of the claims and the serious instrumentation problems with valid measurement of affect variables cross-culturally in SL populations are temporarily ignored, they would in any case appear to have been empirically falsified by a number of studies (see, e.g., d'Anglejan \& Renaud, 1985; Johnson \& Newport, 1989; Morris \& Gerstman, 1986; Oyama, 1978; Purcell \& Suter, 1980; Schmidt, 1981; Strong, 1984).

\section{Input Factors}

Type of input. In an article in which she rejected the idea that there was evidence of an optimal age for SLA, Hatch (1977) nevertheless speculated interestingly on the role of differences in the type of SL input child and adult learners receive as a potential explanation of age-related differences in rate and ultimate attainment, should such differences eventually be shown to exist. Younger learners, especially young children, Hatch suggested, receive better tuned, linguistically less complex input, providing them with more and clearer samples from which to learn the target language.

There seem to be two problems with this explanation. (a) Younger learners receive "simpler" input, but older learners may in fact obtain "better" (more comprehensible) input because they are better able to negotiate it, as shown in a study by Scarcella 
and Higa (1982). (b) There is a relative lack of effect even for quite major input differences in normal and abnormal FL development.

Amount of input. In an interesting discussion of methodological issues in research on the age issue in SLA, Ekstrand (1978) drew attention to the potential confounding of AO, amount of exposure (usually LOR), and subjects' age at testing. Snow (1983) used the claim that younger learners have usually received more input when tested, because earlier AO often means greater LOR, as an argument that adults (who she thinks do as well or better at SLA on less input) are better learners.

The methodological point is an important one. As should be clear from the previous literature review, however, it is not in fact the case that adults are better learners. In addition, (a) adult learners (and many children) with prolonged access to input do not attain target levels (e.g., Pavesi, 1986; Schmidt, 1981; Swain, 1985), and (b) LOR has been found to be unrelated to SLA in several studies (e.g., Johnson \& Newport, 1989; Oyama, 1976, 1978; Patkowski, 1980a; Tahta, Wood, \& Lowenthal, 1981a, 1981b), or, at most, only briefly related (Fathman, 1975).

\section{Cognitive Factors}

Increasing cognitive development has been claimed to underlie decreasing adult language-learning ability by Rosansky (1975), Krashen (1982), and Felix (1981, 1985), although the precise nature of their positions differs. Rosansky and Krashen claim that attainment of Piaget's formal operations stage around the age of puberty involves (among other things) access to metalinguistic skills and the (for adult SLA) counterproductive ability to perceive differences between the FL and SL, not just their underlying similarities. Child FLA/SLA and adult SLA are different processes, it is held, the former utilizing something like a Language Acquisition Device (LAD) or Universal Grammar (UG), and the latter utilizing general problem-solving abilities instead of the LAD (Rosansky) or in competition with UG (Felix).

The rapid "catch-up" effect in "normalized" FLA (e.g., Curtiss, 1977; Lenneberg, 1967; Mason, 1942; Sachs, Bard, \& Johnson, 1981) by older learners and the rate advantage for older over younger SL learners argue for some cognitive role. However, problems with Rosansky and Krashen's position include the following reasons. Doubts exist as to the age at which the formal operations stage is attained, with Piaget specifying 14/15 or older; Ausubel (1968) claiming 10-12, with some individuals never doing so; and some critics (e.g., Brainerd, 1978) disputing Piaget's whole model. While doubts also exist as to the upper and lower age bounds on the supposed sensitive period(s) for SLA, there is clear evidence of initial losses in ability in most areas occurring well before the earliest age posited for the onset of formal operations. Newport and Supalla's (forthcoming) work with ASL suggests that even morphosyntax may need to be begun by age 6 if some individuals are to reach native proficiency.

Supposing Piaget is correct, a one-time, qualitative change such as the onset of formal operations could not account either for an incremental loss in ability across linguistic domains from about ages 6-15, which seems to occur, or for a gradual, 
age-related decline within a linguistic domain, e.g., in syntax, from about ages 6-15 (Johnson \& Newport, 1989). Even if some flexibility is allowed as to both the precise age of transition and the rapidity of passage through cognitive stages, and even if the stages are posited to overlap somewhat, there is nothing either in Piaget's model or, at least, in SLA theorists' claims that are based upon it that could account for losses in ability starting as early as age 6 . This is at the very least an argument for the involvement of other factors in addition to cognitive ones.

In Felix's "competition model" (Felix, 1985) the adult learner's developed inductive general problem-solving (GPS) abilities mature at Piaget's formal operations stage. These abilities are not powerful enough to handle the abstract linguistic properties of natural languages. They are also not restrictive enough, in that their lack of syntactic constraints allows them to consider a wider range of possible grammars than UG allows the infant, leading to inefficient, slower, and incomplete learning. Reliance on these abilities is why adults fail to achieve native-like SL competence.

There are several problems with this position. For example, why should adult learners rely on these less efficient means when, according to Felix, they have triedand-true, perfectly adequate ones (UG) intact? Felix offers no explanation for this, or of why adult learners utilize UG for some structures (and succeed) and GPS abilities for others (and fail), or what (other than post hoc classification, 1985, p. 58) distinguishes the two classes of items. Felix's model, then, is both intuitively unappealing and unfalsifiable (for further discussion, see Bley-Vroman, in press).

While cognitive factors must be implicated in sensitive period effects at some level, there are additional problems with the particular cognitive explanations advanced to date. If cognitive development (as opposed to cognition and cognitive processing; see, e.g., Kennedy, 1988) were heavily implicated in language development, we would expect to see IQ differences having a major influence on rate and achievement in first language acquisition, but do not. We would also expect similar variability in adult SLA, but only do so on tests of reading, grammer, and vocabulary, and not where oral production skills are concerned (Genesee, 1976), implicating agerelated metalinguistic abilities rather than cognitive development and language in general.

If children and adults were learning in fundamentally different ways (children with access to UG, and adults only with GPS abilities), we would expect to see evidence of different acquisition processes and sequences, for example, different errors or stages. In fact, there has been little evidence of such differences to date, at least where child/ adult SLA comparisons are involved (Fathman, 1975; Ritchie, 1978; Singleton, 1989; but cf. Clahsen \& Muysken, 1986; Newport, 1984), presumably because common general cognitive processes are at work in language learning, whether first or second, child or adult, and are not involved in the issue of critical or sensitive periods. It is important to note, however, that there has also been very little research as yet comparing child and adult developmental sequences.

There are some attested errors in the (child and) adult SLA literature that are hard to explain solely as the product of GPS abilities. One example is Turkish learners' observed production of $N o V$ negation in early Swedish SL, given that both languages have post-verbal negation (Hyltenstam, 1977). Another is Italian learners' use of 
nominal and pronominal copies in English relative clauses, when neither Italian nor English allow either (Pavesi, 1986).

The evidence of the long-term superiority in ultimate attainment for young children over late starters in both first and second language development argues against any claim of a permanent advantage for cognitive maturity in the language learner.

\section{Neurological/Neurophysiological Factors}

Plasticity loss with lateralization. With some minor differences among them, Penfield and Roberts (1959), Lenneberg (1967), and Scovel (1969, 1981, 1988), among others have claimed that cerebral dominance is established with the end of lateralization, at around puberty, and that this marks the loss of neural plasticity. This plasticity, it is claimed, during a critical period $(0 / 2-13)$, allows recovery from aphasia, transfer of language function to an undamaged hemisphere, first language development in the mentally retarded, automatic accent-free SLA from mere exposure, and other good things.

There are several problems with this position. (a) The most serious, as Krashen (1973) first pointed out, is that lateralization starts prenatally and is complete in most respects in most individuals by around age 5 , yet these theorists are attempting to explain critical period effects that they maintain appear much later than this, i.e., at puberty. (b) Because plasticity loss is not a sudden, one-time effect, but rather is gradual, it would be difficult to argue that it causes a sudden, one-time loss in SLA abilities, which is what these writers claim occurs. It should also be noted, however, that if the claim of an initial decline in abilities at age 6 in some individuals is correct, lateralization at the earlier age may yet be revived as a possible explanation for some sensitive period effects.

Plasticity loss due to other cerebral changes. Among others, Seliger (1978), using a "multiple critical periods hypothesis," has claimed that the ability to acquire SL skills in general declines (abruptly or incrementally) with a loss of plasticity due to aspects of cerebral maturation unrelated to lateralization. According to Seliger, these may include myelination, thickening of the corpus callosum, and intrahemispheric specialization (localization of function). Evidence of greater plasticity in children comes, e.g., from the near-normal language learning observed in hemidecorticated infants, but not adults (Mehler, Morton, \& Jusczyk, 1984). Localization phenomenaof which lateralization is just one, albeit major, stage-lasts into the teens, as does the incremental loss of plasticity associated with them.

Of the factors discussed by Seliger (1978), myelination seems particularly promising. Myelination is described by Maxwell (1984, pp. 45-47) as the process during which the axon projections of many neurons undergo anatomical and chemical changes as they are wrapped in myelin sheaths consisting of lipids and proteins, something that begins in the fetus and takes several decades to complete. Interestingly, the sequence in which neural pathways are myelinated seems to depend on their importance for human development, with those involved in satisfying basic physiological needs being myelinated before those involved in regulating complex mental 
activity. Completion of myelination has been interpreted by Lecours (1975) as functional maturation of the brain, and as resulting in neural space committed in an invariable path. While the functional relevance of myelination to human development is still poorly understood, it has been suggested that the process may be implicated in the decline of the language learning capacity:

With respect to linguistic development, the long projection axons of the cortex are important for establishing communicative channels between the language centers and other centers involved in neuromotor control. Some investigators have believed that only at a very young age, while the cell systems of such pathways are still developing, can new language centers be formed (Penfield \& Roberts, 1959; Lenneberg, 1967). (Maxwell, 1984, p. 47)

Diller (1981) claimed that the plasticity of the cell systems linking language and neuromotor control centers falls off sharply after the age of 6-8 years. Part of the attraction of myelination as a potential neurophysiological correlate of sensitive period effects is its duration and progressive nature.

Like other explanations, however, plasticity loss as a function of the myelination process is not without problems. (a) The position is largely speculative, given the current state of knowledge and instrumentation problems in neurophysiology. (See Jacobs, 1988, for a review of recent developments in this area.) (b) It is based mostly on pathological evidence, with the attendant dangers of generalizing to normal populations. There is obviously a danger in extrapolating from the abnormal to the normal brain, as in, e.g., use of results on the recovery from hemispherectomy. In other words, is the plasticity usable in non-insult situations? (c) Little is currently known about neurological changes coinciding specifically with the onset of puberty (Whitaker, Bub, \& Leventer, 1981) or with any other ages supposedly associated with declines in language learning ability, (although, again, see Jacobs, 1988, for promising recent developments). The human brain reaches approximately $90 \%$ of its adult size and weight and completes most aspects of lateralization at about $5 / 6$, the age that the first maturational constraints (for SL and second dialect phonology) seem to set in. On the other hand, the total myelination process, which has been proposed here as a promising neurophysiological explanation, lasts throughout the relevant age range, but also well beyond the close of the latest posited sensitive period for language development, that for morphology and syntax at about 15. (d) As was the case with affect variable explanations, a general loss of cerebral plasticity says nothing about why particular linguistic systems, and, within systems, particular structures, are affected sequentially and differentially. (e) While typically advanced as a unique explanation of maturational constraints, neurophysiological processes require cognitive consequences if they are to have anything to do with sensitive periods or any other language issues, and vice versa. Thus, an independent neurophysiological account is probably somewhat artificial or, at best, partial.

\section{CONCLUSIONS}

There is considerable evidence of maturational constraints and a sensitive period for first language development. Data on various feral children, Genie, deaf children of 
hearing adults producing "home sign," and deaf individuals learning ASL all show that language learning is typically somewhat irregular and incomplete if begun late (around age 6-8), and that the irregularities and shortfalls from native-like levels of ultimate attainment become more pronounced with increasing $\mathrm{AO}$ and are severe in cases of postpubertal learning. The very same late first language starters often exhibit an accelerated rate of development compared to younger learners, a fact which is not, however, taken as disproving the existence of a sensitive period for FL development in light of the ultimate attainment data.

The picture for SLA is similar. While some learners who begin late reach very high standards, the SL data, too, are consistent with the existence of one or more sensitive periods for SLA, with approximately the same lower and upper age bounds as those for FL development. The ability to attain native-like phonological abilities in an SL begins to decline by age 6 in many individuals and to be beyond anyone beginning later than age 12, no matter how motivated they might be or how much opportunity they might have. Native-like morphology and syntax only seem to be possible for those beginning before age 15 . As with first language development, adults and older children learn early SL morphology and syntax faster than younger children. The rate advantage is generally only temporary, however, and, "faster" again does not mean "better," as shown by the poorer long-term achievement of older learners and by the fact that only young starters can attain native-like proficiency. The first and second language data are consistent, in other words, with the so-called "maturational state hypothesis."

Affective, input, cognitive, and neurological variables are four popular sources of accounts of these declines in language learning abilities. All have problems, however. Affective and input accounts and the particular cognitive explanations advanced to date suffer from a variety of logical and empirical flaws and seem unlikely to prove viable as unique sources of explanation for age differences. Positing a role for neurological factors with cognitive consequences, on the other hand-specifically incremental losses of plasticity with increasing brain maturation, possibly associated with myelination-if only by default, seems a more defensible position. Biological accounts seem reasonable in the first language cases, since (presumably) no one is inclined to argue that, say, the deaf youngsters are less motivated to learn than their hearing age peers, since input is no problem in most cases (e.g., normal FL acquisition of ASL), and since cognitive factors, as shown by the rate advantage data, if anything favor these older FL learners. If this explanation is acceptable for the FL cases, it is presumably feasible for the SL data, too. It is, at the very least, yet to be disconfirmed.

The neural plasticity position is not without problems of its own, however, notably its lack of much empirical content and of precisely synchronized relationships with claimed losses in language learning abilities, themselves as yet only roughly tied to precise ages. This situation, one must assume, is due to the state of knowledge in neurophysiology rather than to the nonexistence of such relationships. There is also a need to tie the relevant neurological changes together with age-related differences in one or more aspects of cognition or processing, since a brain change with no cognitive consequences will have nothing to do with sensitive periods or any other language issue. 
Finally, several methodological implications are also clear from the SLA literature reviewed. Data in some crucial areas, notably lexis, collocation, discourse, and pragmatics, are sparse, and a lot more work is also still needed on ultimate attainment in morphology and syntax. Some of the research in these areas should focus on very advanced learners. In order to probe subtle areas, researchers will need to use precisely targeted elicitation instruments, especially grammaticality and appropriacy judgment measures, and not just production data and global proficiency ratings. The goal is to determine whether the very best SL learners actually have native-like competence, or whether, as is claimed here, they can pass as NSs only when limited samples of their performance are sampled, using production rather than comprehension data, with the attendant opportunities for avoidance that those allow. The fine detail sought in many of the judgment tasks will also make it preferable to conduct at least some of the work in relatively homogeneous speech communities whose native variety was the SL target for the subjects, and to concentrate on items whose grammatical status for monolingual native speakers is first established unambiguously using baseline data elicited with the same tasks. These are rigorous criteria for researchers to meet, but they are necessary if findings in this important area are to be rid of controversy.

\section{REFERENCES}

Adiv, E. (1980). An analysis of second language performance in two types of immersion programs. Unpublished $\mathrm{PhD}$ thesis, McGill University, Montreal.

Asher, J., \& Garcia, R. (1969). The optimal age to learn a foreign language. Modern Language Journal, 53, 334-341.

Asher, J., \& Price, B. (1967). The learning strategy of total physical response: Some age differences. Child Development, 38, 1219-1227.

Ausubel, D. P. (1968). Educational psychology: A cognitive view. New York: Holt, Rinehart and Winston.

Bateson, P. P. G. (1973). Internal influences on early learning in birds. In R. A. Hinde \& Stephenson-Hinde (Eds.), Constraints on learning (pp. 77-102). New York: Academic.

Bellugi, U. (1967). The acquisition of negation. Unpublished $\mathrm{PhD}$ thesis, Harvard University, Cambridge, MA.

Bland, M., \& Keislar, E. (1966). A self-controlled audio-lingual program for children. French Review, 40, 266276.

Bley-Vroman, R. (in press). The logical problem of foreign language learning. Linguistic Analysis.

Brainerd, C. J. (1978). Learning research and Piagetian theory. In L. S. Siegel \& C. J. Brainerd (Eds.), Alternatives to Piaget: Critical essays on the theory (pp. 69-109). New York: Academic.

Brown, H. D. (1979, February). A socioculturally determined critical period for second language acquisition. Paper presented at the 13th Annual TESOL Convention, Boston, MA.

Burstall, C., Jamieson, M., Cohen, S., \& Hargreaves, M. (1974). Primary French in the balance. Windsor, UK: National Foundation for Educational Research.

Clahsen, H., \& Muysken, P. (1986). The availability of universal grammar to adult and child learners-A study of the acquisition of German word order. Second Language Research, 2, 93-119.

Cochrane, R. (1980). The acquisition of $/ \mathrm{r} /$ and $/ /$ by Japanese children and adults learning English as a second language. Journal of Multilingual and Multicultural Development, 1, 331-360.

Collier, V. (1987). Age and rate of acquisition of second language for academic purposes. TESOL Quarterly, 21, $617-641$.

Colombo, J. (1982). The critical period concept: Research, methodology, and theoretical issues. Psychological Bulletin, 91, 260-275.

Cook, V. (1988). Chomsky's universal grammar. Oxford: Blackwell.

Coppieters, R. (1987). Competence differences between native and fluent non-native speakers. Language, 63 , $544-573$.

Cummins, J. (1981). Age on arrival and immigrant second language learning in Canada. Applied Linguistics, II, 132-149. 
Curtiss, S. R. (1977). Genie: A linguistic study of a modern day "wild child." New York: Academic.

Curtiss, S. R. (1980). The critical period and feral children. UCLA Working Papers in Cognitive Linguistics, 2, 21-36.

Curtiss, S. R. (1982). Developmental dissociation of language and cognition. In L. K. Obler \& L. Menn (Eds.), Exceptional languages and linguistics (pp. 285-312). New York: Academic.

Curtiss, S. R. (1988). Abnormal language acquisition and the modularity of language. In F. J. Newmeyer (Ed.), Linguistics: The Cambridge Survey: Vol. 2. Linguistic theory: Extensions and implications (pp. 96-116). Cambridge: Cambridge University Press.

D'Anglejan, A., \& Renaud, C. (1985). Learner characteristics and second language acquisition: A multivariate study of adult immigrants and some thoughts on methodology. Language Learning, 35, 1-19.

David, S. (1985). The acquisition of the phonological features of a second dialect. Unpublished master's thesis, University of South Carolina, Columbia.

Diller, K. (1981). 'Natural methods' of foreign language teaching: Can they exist? What criteria must they meet? In H. Winnitz (Ed.), Native language and foreign language acquisition. Annals of the New York Academy of Sciences, 379, 75-91.

Ekstrand, L. (1976). Age and length of residence as variables related to the adjustment of migrant children, with special reference to second language learning. In $\mathrm{G}$. Nickel (Ed.), Proceedings of the Fourth International Congress of Applied Linguistics (Vol. 3, pp. 179-198). Stuttgart: Hochschulverlag.

Ekstrand, L. (1978). English without a book revisited: The effect of age on second language acquisition in a formal setting. Didakometry, 60. Malmo, Sweden: Department of Educational and Psychological Research, School of Education, Malmo University.

Ellis, R. (1985). Understanding second language acquisition. Oxford: Oxford University Press.

Ervin-Tripp, S. M. (1974). Is second language learning like the first? TESOL Quarterly, 8, 111-127.

Fathman, A. K. (1975). The relationship between age and second language learning ability. Language Learning, 25, 245-253.

Fathman, A. K., \& Precup, L. (1983). Influences of age and setting on second language oral proficiency. In K. M. Bailey, M. H. Long, \& S. Peck (Eds.), Second language acquisition studies (pp. 151-161). Rowley, MA: Newbury House.

Feldman, H., Goldin-Meadow, S., \& Gleitman, L. R. (1978). Beyond Herodotus: The creation of language by linguistically deprived deaf children. In A. Locke (Ed.), Action, gesture and symbol: The emergence of language (pp. 102-123). London: Academic.

Felix, S. W. (1981). On the (in)applicability of Piagetian thought to language learning. Studies in Second Language Acquisition, 3, 201-220.

Felix, S. W. (1985). More evidence on competing cognitive systems. Second Language Research, 1, 47-72.

Fillmore, C. J., Kempler, D., \& Wang, W. S-Y. (1979). Individual differences in language ability and language behavior. New York: Academic.

Flege, J. E. (1987). A critical period for learning to pronounce foreign languages? Applied Linguistics, 8, 162177.

Florander, J., \& Jansen, M. (1969). Skoleforsog i engelsk 1959-1965. Unpublished manuscript, Denmark Institute of Education, Copenhagen.

Genesee, F. (1976). The role of intelligence in second language learning. Language Learning, 26, 267-280.

Genesee, F. (1983). Bilingual education of majority language children: The immersion experiments in review. Applied Psycholinguistics, 4, 1-46.

Genesee, F. (1988). Neuropsychology and second language acquisition. In L. M. Beebe (Ed.), Issues in second language acquisition: Multiple perspectives (pp. 81-112). Cambridge, MA: Newbury House.

Gleitman, L. R. (1986). Biological programming for language learning. In S. L. Friedman, K. A. Klivington, \& R. W. Peterson (Eds.), The brain, cognition, and education (pp. 119-149). New York: Academic.

Goldin-Meadow, S. (1982). The resilience of recursion: A study of a communication system developed without a conventional language model. In E. Wanner \& L. R. Gleitman (Eds.), Language acquisition: Siate of the art (pp. 51-77). Cambridge: Cambridge University Press.

Gould, J., \& Marler, P. (1987, January). Learning by instinct. Scientific American, 256, 74-85.

Gregg, K. R. (1984). Krashen's monitor and Occam's razor. Applied Linguistics, 5, 79-100.

Grinder, R., Otomo, A., \& Toyota, W. (1962). Comparisons between second, third and fourth grade children in the audio-lingual learning of Japanese as a second language. The Journal of Educational Research, 56, 463-469.

Guiora, A., Ben-Hallahmi, B., Brannon, R., Dull, C., \& Scovel, T. (1972). The effects of experimentally induced changes in ego states on pronunciation ability in a second language: An exploratory study. Comprehensive Psychiatry, 13, 421-428.

Guiora, A., \& Schonberger, R. (1989, May). Native pronunciation of bilinguals. Paper presented at the first annual JAAL conference, Aoyama Gakuin University, Tokyo. 
Harley, B. (1982). Age-related differences in the acquisition of the French verb system by anglophone students in French immersion programs. Unpublished PhD thesis, University of Toronto.

Harley, B. (1986). Age in second language acquisition. Clevedon, UK: Multilingual Matters.

Hatch, E. M. (1977). Optimal age or optimal learners? Workpapers in TESL, 11, 45-56.

Hatch, E. M. (1983). Psycholinguistics: $A$ second language perspective. Rowley: MA: Newbury House.

Hinde, R. A. (1970). Animal behavior (2nd ed.). New York: McGraw-Hill.

Hyltenstam, K. (1977). Implicational patterns in interlanguage syntax variation. Language Learning, 27, 383411.

Immelmann, K., \& Suomi, S. (1981). Sensitive phases in development. In K. Immelmann, G. Barlow, L. Petrinovich, \& L. Main (Eds.), Behavioral development: The Bielefeld Interdisciplinary Project. Cambridge: Cambridge University Press.

loup, G. (1984). Is there a structural foreign accent? A comparison of syntactic and phonological errors in second language acquisition. Language Learning, 34, 1-17.

Jacobs, B. (1988). Neurobiological differentiation of primary and secondary language acquisition. Studies in Second Language Acquisition, 10, 303-337.

James, S. L., \& Kahn, L. M. L. (1982). Grammatical morpheme acquisition: An approximate invariant order? Journal of Psycholinguistic Research, 1/, 381-388.

Johnson, J. S., \& Newport, E. L. (1989). Critical period effects in second language learning: The influence of maturational state on the acquisition of English as a second language. Cognitive Psychology, 21, 60-99.

Jones, M., \& Quigley, S. (1979). The acquisition of question formation in spoken Spanish and American Sign Language by two hearing children of deaf parents. Journal of Speech and Hearing Disorders, 44, 196208.

Kennedy, B. L. (1988). Adult versus child L2 acquisition: An information-processing approach. Language Learning, 38, 477-495.

Krashen, S. D. (1973). Lateralization, language learning and the critical period: Some new evidence. Language Learning, 23, 63-74.

Krashen, S. D. (1982). Accounting for child-adult differences in second language rate and attainment. In S. D. Krashen, R. C. Scarcella, \& M. H. Long (Eds.), Child-adult differences in second language acquisition (pp. 202-226). Rowley, MA: Newbury House.

Krashen, S. D., Long, M. H., \& Scarcella, R. C. (1979). Age, rate, and eventual attainment in second language acquisition. TESOL Quarterly, 13, 573-582.

Krashen, S. D., Scarcella, R. C., \& Long, M. H. (Eds.). (1982). Child-adult differences in second language acquisition. Rowley, MA: Newbury House.

Lamendella, J. (1977). General principles of neurofunctional organization and their manifestation in primary and non-primary acquisition. Language Learning, 27, 155-196.

Lecours, A. R. (1975). Myelogenetic correlates of the development of speech and language. In E. H. Lenneberg \& E. Lenneberg (Eds.), Foundations of language development (Vol. 1). New York: Academic.

Lenneberg, E. H. (1967). Biological foundations of language. New York: Wiley.

Lowenthal, K., \& Bull, D. (1984). Imitation of foreign sounds: What is the effect of age? Language and Speech, 27, 95-97.

Major, R. (1987). Foreign accent: Recent research and theory. International Review of Applied Linguistics, 15, 185-202.

Mason, M. (1942). Learning to speak after six and one half years of silence. Journal of Speech Disorders, 7 , 295-304.

Matsunobu, J. T. (1981). A sore thumb? Identifying the ESL writer. Unpublished paper, University of Pennsylvania, Philadelphia.

Maxwell, D. L. (1984). The neurology of learning and language disabilities: Developmental considerations. In G. P. Wallach \& K. G. Butler (Eds.), Language learning disabilities in school-age children (pp. 35-59). London: Williams and Wilkins.

Mayberry, R., Fischer, S., \& Hatfield, N. (1983). Sentence repetition in American Sign Language. In J. Kyle \& B. Woll (Eds.), Language in sign: International perspectives on sign language (pp. 83-97). London: Croom Helm.

McKinney, V. (1983). First language learning in deaf persons beyond the critical period. Unpublished PhD thesis, Clairemont Graduate School, Clairemont, CA.

McLaughlin, B. (1984). Second-language acquisition in childhood: Volume 1. Preschool children (2nd ed.). Hillsdale, NJ: Erlbaum.

Mehler, J., Morton, J., \& Jusczyk, P. (1984). On reducing language to biology. Cognitive Neuropsychology, 1, 83-116.

Mimura, K. (1986). Development of visual pattern discrimination in the fly depends on light experience. Science, 232, 83-85. 
Morris, B. S. K., \& Gerstman, L. J. (1986). Age contrasts in the learning of language-relevant materials: Some challenges to critical period hypotheses. Language Learning, 36, 311-352.

Neufeld, G. (1977). Language learning ability in adults: A study on the acquisition of prosodic and articulatory features. Working Papers on Bilingualism, 12, 45-60.

Neufeld, G. (1978). On the acquisition of prosodic and articulatory features in adult language learning. Canadian Modern Language Review, 34, 163-174.

Neufeld, G. (1979). Towards a theory of language learning ability. Language Learning, 29, 227-241.

Newport, E. (1984). Constraints on learning: Studies in the acquisition of American Sign Language. Paper and Reports on Child Language Development, 23, 1-22.

Newport, E., \& Supalla, T. (forthcoming). Critical period effects in the acquisition of a primary language.

Olson, L., \& Samuels, S. J. (1973). The relationship between age and accuracy of foreign language pronunciation. Journal of Psycholinguistic Research, 66, 263-267.

Oyama, S. C. (1976). A sensitive period for the acquisition of a phonological system. Journal of Psycholinguistic Research, 5, 261-283.

Oyama, S. C. (1978). The sensitive period and comprehension of speech. Working Papers on Bilingualism, 16, $1-17$.

Oyama, S. C. (1979). The concept of the sensitive period in developmental studies. Merrill-Palmer Quarterly, 25, 83-103.

Patkowski, M. (1980a). The sensitive period for the acquisition of syntax in a secondary language. Unpublished PhD thesis, New York University, New York.

Patkowski, M. (1980b). The sensitive period for the acquisition of syntax in a second language. Language Learning, 30, 449-472.

Patkowski, M. (1982). The sensitive period for the acquisition of syntax in a second language. In S. D. Krashen, R. C. Scarcella, \& M. H. Long (Eds.), Child-adult differences in second language acquisition (pp. 52-63). Rowley, MA: Newbury House.

Patkowski, M. (1990). Age and accent in a second language: A reply to James Emil Flege. Applied Linguistics, $11,73-89$.

Pavesi, M. (1986). Markedness, discoursal modes, and relative clause formation in a formal and an informal context. Studies in Second Language Acquisition, 8, 38-55.

Payne, A. (1980). Factors controlling the acquisition of the Philadelphia dialect by out-of-state children. In W. Labov (Ed.), Locating language in time and space (pp. 143-178). New York: Academic.

Penfield, W., \& Roberts, L. (1959). Speech and brain mechanisms. New York: Atheneum.

Purcell, E. T., \& Suter, R. W. (1980). Predictors of pronunciation accuracy: A reexamination. Language Learning, 30, 271-287.

Ramirez, A. G., \& Politzer, R. L. (1978). Comprehension and production in English as a second language by elementary school children and adolescents. In E. M. Hatch (Ed.), Second language acquisition: A book of readings (pp. 313-332). Rowley, MA: Newbury House.

Ramsey, C. A., \& Wright, E. N. (1974). Age and second language learning. The Journal of Social Psychology, 94, 115-121.

Ritchie, W. C. (1978). The right roof constraint in an adult-acquired language. In W. C. Ritchie (Ed.), Second language acquisition research (pp. 33-63). New York: Academic.

Rosansky, E. (1975). The critical period for the acquisition of language: Some cognitive developmental considerations. Working Papers on Bilingualism, 6, 10-23.

Sachs, J., Bard, B., \& Johnson, M. L. (1981). Language learning with restricted input: Case studies of two hearing children of deaf parents. Applied Psycholinguistics, 2, 33-54.

Scarcella, R. C. (1983). Discourse accent in second language performance. In S. Gass \& L. Selinker (Eds.), Language transfer in language learning (pp. 306-322). Rowley, MA: Newbury House.

Scarcella, R. C., \& Higa, C. A. (1982). Input and age differences in second language acquisition. in S. D. Krashen, R. C. Scarcella, \& M. H. Long (Eds.), Child-adult differences in second language acquisition (pp. 175-201). Rowley, MA: Newbury House.

Schiff, N. (1979). The influence of deviant maternal input on the development of language during the preschool years. Journal of Speech and Hearing Research, 22, 581-603.

Schmid, E. (1986). A comparative study of children's and adults' acquisition of tone accents in English. Language Learning, 36, 185-210.

Schmidt, R. W. (1981). Interaction, acculturation and the acquisition of communicative competence. University of Hawaii Working Papers in Linguistics, 13, 29-77.

Schumann, J. H. (1975). Affective factors and the problem of age in second language acquisition. Language Learning, 25, 209-235.

Scovel, T. (1969). Foreign accents, language acquisition, and cerebral dominance. Language Learning, 19, 245254. 
Scovel, T. (1981). The recognition of foreign accents in English and its implications of psycholinguistic theories of language acquisition. In J-G. Savard \& L. Laforge (Eds.), Proceedings of the 5th Congress of AlLA (pp. 389-401). Laval, Canada: University of Laval Press.

Scovel, T. (1988). A time to speak. A psycholinguistic inquiry into the critical period for human speech. Cambridge, MA: Newbury House.

Seliger, H. W. (1978). Implications of a multiple critical periods hypothesis for second language learning. In W. Ritchie (Ed.), Second language acquisition research (pp. 11-19). New York: Academic.

Seliger, H. W., Krashen, S. D., \& Ladefoged, P. (1975). Maturational constraints in the acquisition of second language accent. Language Sciences, 36, 20-22.

Seright, L. (1985). Age and aural comprehension achievement in francophone adults learning English. TESOL Quarterly, 19(3), 455-473.

Singleton, D. (1989). Language acquisition. The age factor. Clevedon, UK: Multilingual Matters.

Slobin, D. I. (1982). Universal and particular in the acquisition of language. In E. Wanner \& L. R. Gleitman (Eds.), Language acquisition: State of the art (pp. 128-170). Cambridge: Cambridge University Press.

Snow, C. E. (1983). Age differences in second language acquisition: Research findings and folk psychology. In K. M. Bailey, M. H. Long, \& S. Peck (Eds.), Second language acquisition studies (pp. 141-150), Rowley, MA: Newbury House.

Snow, C. E. (1987). Relevance of the notion of a critical period to language acquisition. In M. Bernstein (Ed.), Sensitive periods in development: An interdisciplinary perspective (pp. 183-209). Hillsdale, NJ: Erlbaum.

Snow, C. E., \& Hoefnagel-Hohle, M. (1977). Age differences and the pronunciation of foreign sounds. Language and Speech, 20, 357-365.

Snow, C. E., \& Hoefnagel-Hohle, M. (1978). The critical period for language acquisition: Evidence from second language learning. Child Development, 49, 1114-1128.

Strong, M. (1984). Integrative motivation: Cause or result of successful second language acquisition? Language Learning, 34, 1-14.

Studdert-Kennedy, M. (1985). The beginnings of speech. In K. Immelman, G. Barlow, L. Petrinovich, \& L. Main (Eds.), Behavioral development: The Bielefeld Interdisciplinary Project (pp. 533-561). Cambridge: Cambridge University Press.

Swain, M. (1985). Communicative competence: Some roles of comprehensible input and comprehensible output in its development. In S. M. Gass \& C. G. Madden (Eds.), Input in second language acquisition (pp. 235-253). Rowley, MA: Newbury House.

Tahta, S., Wood, M., \& Lowenthal, K. (1981a). Age changes in the ability to replicate foreign pronunciation and intonation. Language and Speech, 24, 363-372.

Tahta, S., Wood, M., \& Lowenthal, K. (1981b). Foreign accents: Factors relating to transfer of accent from the first language to a second language. Language and Speech, 24, 265-272.

Taylor, B. (1974). Toward a theory of language acquisition. Language Learning, 24, 23-36.

Thogmartin, C. (1982). Age, individual differences in musical and verbal aptitude, and pronunciation achievement by elementary school children learning a foreign language. International Review of Applied Linguistics, $20,66-72$.

Toutaiolepo, V. J. (1984). Stalking the wild ESL writer. Unpublished paper, University of Hawaii, Honolulu.

Walberg, H., Hase, K., \& Pinzur Rasher, S. (1978). English acquisition as a diminishing function of experience rather than age. TESOL Quarterly, 12, 427-437.

Wald, B. (1986). Syntactic development after childhood: Beyond the vernacular? In D. Sankoff (Ed.), Diversity and diachromy. Current issues in linguistic theory (Vol. 53, pp. 153-170). Amsterdam: John Benjamins.

Weber-Olsen, M., \& Ruder, K. (1980). Acquisition and generalization of Japanese locatives by English speakers. Applied Psycholinguistics, 3, 127-198.

Whitaker, H., Bub, D., \& Leventer, S. (1981). Neurolinguistic aspects of language acquisition and bilingualism. Annals of the New York Academy of Sciences, 379, 59-74.

White, L. (1985). The "pro-drop" parameter in adult second language acquisition. Language Learning, 35, 4762.

Woodward, J. C. (1973). Some characteristics of pidgin sign English. Sign Language Studies, 3, 39-59.

Yamada, J., Takatsuka, S., Kotabe, N., \& Kuruse, J. (1980). On the optimum age for teaching foreign vocabulary to children. International Review of Applied Linguistics, 28, 245-247.

Young, R. (1981). Sign language acquisition in a deaf adult: A test of the critical period hypothesis. Unpublished $\mathrm{PhD}$ thesis, University of Georgia, Athens. 